\title{
Article \\ Optimal Multi-Operation Energy Management in Smart Microgrids in the Presence of RESs Based on Multi-Objective Improved DE Algorithm: Cost-Emission Based Optimization
}

\author{
Mohammad Ghiasi ${ }^{1}$ (D), Taher Niknam ${ }^{1, *}$, Moslem Dehghani ${ }^{1}$ (D), Pierluigi Siano ${ }^{2, *(D)}$, Hassan Haes Alhelou ${ }^{3, *(D)}$ \\ and Amer Al-Hinai 4,5 \\ 1 Department of Electrical and Electronic Engineering, Shiraz University of Technology, \\ Shiraz 7155713876, Iran; m.ghiasi@sutech.ac.ir (M.G.); mo.dehghani@sutech.ac.ir (M.D.) \\ 2 Department of Management and Innovation Systems, University of Salerno, 84084 Salerno, Italy \\ 3 Department of Electrical and Electronic Engineering, University College Dublin, Dublin, Ireland \\ 4 Electrical \& Computer Engineering Department, Sultan Qaboos University, Alkhoud 123, Oman; \\ hinai@squ.edu.om \\ 5 Sustainable Energy Research Center, Sultan Qaboos University, Alkhoud 123, Oman \\ * Correspondence: niknam@sutech.ac.ir (T.N.); psiano@unisa.it (P.S.); hassan.haesalhelou@ucd.ie (H.H.A.)
}

check for

updates

Citation: Ghiasi, M.; Niknam, T; Dehghani, M.; Siano, P.; Haes Alhelou, H.; Al-Hinai, A. Optimal Multi-Operation Energy Management in Smart Microgrids in the Presence of RESs Based on Multi-Objective Improved DE Algorithm: Cost-Emission Based Optimization. Appl. Sci. 2021, 11, 3661. https:// doi.org/10.3390/app11083661

Academic Editor: Hannu Laaksonen

Received: 28 March 2021

Accepted: 17 April 2021

Published: 19 April 2021

Publisher's Note: MDPI stays neutral with regard to jurisdictional claims in published maps and institutional affiliations.

Copyright: (c) 2021 by the authors. Licensee MDPI, Basel, Switzerland. This article is an open access article distributed under the terms and conditions of the Creative Commons Attribution (CC BY) license (https:// creativecommons.org/licenses/by/ $4.0 /)$.

\begin{abstract}
Today, in various leading power utilities in developing countries, achieving optimal operational energy management and planning, taking into account the costs reduction of generation, transmission and distribution of electricity, and also reducing the emission of an environmental pollutant becomes more and more important. Optimal use of renewable energy sources (RESs) is an effective way to achieve these goals. In this regard, in this research article, an improved multiobjective differential evolutionary (IMODE) optimization algorithm is suggested and performed to dispatch electricity generations in a smart microgrid (MG) system, taking into account economy and emission as competitive issues. In this paper, a nonlinear equation of multi-objective optimization issue with various equality and inequality limitations is formulated in order to lower the total operational costs of the MG considering environmental pollution effects simultaneously. In order to address the issue of optimal operation of the MG in single-objective and multi-objective forms, an intelligent method according to the improved differential evolutionary (IDE) optimization is utilized and performed and the proposed algorithm is implemented on different problems. First, it is assumed that there is no limit to the exchange of power overhead, and secondly, the limitation of power exchange with the upstream grid is considered. In multi-objective mode, these two modes are also considered. In order to show the impact of renewable energy on the cost, in the third part of the simulations, the operation is solved with maximum participation of renewable energy sources. In the final section, the sensitivity analysis on the number of populations in this problem is performed. The obtained results of the simulation are compared to differential evolutionary (DE) and particle swarm optimization (PSO) techniques. The effectiveness of the suggested multi-operational energy management method is confirmed by applying a study case system.
\end{abstract}

Keywords: multi-operational energy management; IDE; RES; smart microgrid; optimization; cost effective; gas emission

\section{Introduction}

In recent years, novel methods have been conducted in power system utilities towards distributed generation (DG) in energy conversion systems (ECSs) which mean that they are located close to the electricity customers; besides, large power plant units have been substituted by smaller ones. In addition to this, for consumers, the potential of lower costs, higher reliability of services and power quality, increasing in power efficiency and power independency can be the reasons for higher interests in DGs. Using RESs and green powers, 
including wind and photovoltaics, can offer notable environmental advantages [1-4]. In this way, MG can act as a concept that gives an effective solution for integrating renewable DGs into the major power and energy network and offers the requirements of next generation power systems [5-8]. Overall, a MG network system consists of a number of homes, industrial, and commercial consumers, as well as DGs (essentially RESs), with a central control system, which typically uses one or more battery energy storage (ES) systems as backup $[9,10]$.

Therefore, it can be stated that power system optimizers in energy management systems, combined with the integration of next type sources that form a smart MG system, have the potential to serve as a practical instrumentation for achieving sustainable development goals. In addition, with the lower incorporation of RESs, the total impact on power network operation will be limited; however, as their influence grows, their mutual impacts can be also increased [11-13]. As a result, there is a pivotal requirement for more accurate and optimal planning of energy management in MGs which help to improve the power system operation in economy and emission $[14,15]$. Therefore, it can be a necessary issue for developing more trusted approaches in optimization issues.

On the other hand, power system operators and electricity industry policymakers around the world face different problems. Currently, only one-third of the fuel used is converted to electrical energy and the lost heat is not recovered. Part of the power output of power plants is lost during transmission to loads and a significant percentage of the power plant capacity is used only for peak hours. Energy shortages and environmental pollutants are also among these problems. The existing electrical energy system is the product of the development of technology and the rapid growth of various infrastructures in different countries over the past few decades [16-19]. Although power companies are located in different regions, they typically use lookalike approaches in their energy management systems. However, the recent development of the electrical and energy system was notably affected by the economic, policy, and geographical issues that are unique to every utility $[1,11,20,21]$.

Overall, many optimal power dispatch techniques and optimization algorithms addressed the case of single objective of problem. Such algorithms and methods have been encountered the issue of deciding the most cost-effective units to dispatch [22-24]. In this field of study, Boqiang and Chuanwen [25] have presented a hierarchical method for economical dispatch while taking into account the risk management in electricity market. The author of the paper [26] suggested a linear optimization process where a single objective has been considered at any time. In reference [27], authors have performed neural network $(\mathrm{NN})$ approach algorithm for treating the economic dispatch issues. In paper [28], a revised adaptive NN based technique has been developed to deal with the dispatch problem. In order to have an economic operation and energy management for cogeneration power plant units, due to the environmental impact of this type of power plant, a model based on nonlinear programming in the reference [29] has been proposed. In addition, in several articles, experts have tried to improve the obtained results by defining a one objective function $(\mathrm{OF})$ using optimization evolutionary approaches, according to the defined functions in their researches. For example, an improved PSO algorithm has been used in reference [30] to perform economic dispatch of power plant units considering their constraints. Likewise, in the papers [31,32], evolutionary programming approaches were applied for solving these kinds of problems.

In recent years, a combination of economic and environmental dispatch (CEED) has been suggested as an efficient way to address the optimal dispatch and energy management issues since multi-objective optimizers could decrease the air pollution with lower operational costs. From this point of view, optimized power systems are capable of economic performance by considering various criteria of inevitable limitations while causing low negative environmental effects. Today, different optimization strategies have been performed to deal with the optimal dispatch and energy management issues in more effective manners [33]. For instance, optimal scheme methods under the carbon-emission 
based utilizing metaheuristic algorithms have been suggested by Sadegheih [34]. Similarly, authors of the paper [35] have surveyed different methods like genetic algorithm (GA), in that parameters have been regulated with fuzzy logic (FL) concepts. Additionally, in order to solve an economic and environmental dispatch (EED) issue, an improved decision shuffle frog leaping algorithm has been used in reference [36]. In paper [37], also, to address the EED issue, a stochastic method taking into account uncertainties was proposed; and in [38], authors performed a detailed research regarding evolutionary programming algorithm i.e., ant colony optimization (ACO) and GA to solve EED problems have been implemented. For optimal dispatch and operating electric energy, various multi-objective evolutionary algorithms were also suggested in the reference [39]. In reference [40], authors focused on the benefits of using neural-fuzzy methods to find an acceptable way to address multi-objective generation and energy management issue. The impacts of electric vehicles, smart homes, and smart buildings, including smart hospitals and smart schools, have been examined, optimized, and managed in references [41,42].

Among the above-mentioned optimization techniques, differential evolutionary (DE) algorithm has been noticeably utilized in optimal operation and energy management issue, basically because of its population-based search ability and higher efficiency, more speed of convergence, and robustness; therefore, an improved multi-objective differential evolution (IMODE) technique is suggested in this research. To dominate the issues of falling into the local optimum and premature convergence, in our proposed IMODE algorithm, an immune operation technique is introduced to power the local search capability and improve optimization precision. The suggested method is successfully carried out on various case studies, and the efficiency measures consisting of convergence and divergence metrics are computed. Besides, the multi-objective optimization of a multi-operation energy management in SGs in presence of RESs procedure is performed using the presented IMODE algorithm. In order to show the impact of renewable energy on the cost, in the simulations, the operation is solved with maximum participation of RESs. In the final section, the sensitivity analysis on the number of populations in this problem is performed.

\section{Materials and Methods}

In this section, the problem of optimal operation, energy management, and power dispatch in MGs considering environmental and economic indicators will be implemented as a multi-objective optimization formulation. In addition, MG modeling and proposed improved differential evolutionary (IDE) optimization algorithm are introduced. Within the multi-objective optimization process, both opposing goals should be considered, including the total operating expense of the MG and the air emission of pollutants, which have to be minimized simultaneously while satisfying the limitations of the system. Hence, we should formulate these problems as the following functions.

\subsection{Objective Functions (OFs)}

The problem of optimizing energy and operation management can be defined as a multi-objective optimization problem by considering both environmental and economic criteria in a smart MG at the same time. In this regard, two different objectives, one being the operating costs of the network and the other being the emission of environmental pollutants, should be minimized while meeting the limitations of the system. Hence, the mathematical forms of this issue can be stated in the following subsections:

\subsubsection{Objective 1: Minimizing the Total Costs of Operating in MG}

The total expenses of operation in MG consist of the fuel costs of the power plant units and their costs of start-up and shut-down. The result of this part is a collection of optimal load flow from energy resources to the loads economically for a specific time period. Storage system options, in addition to distributed generations (DGs), can be utilized to compensate expensive power buying from the company and storing power in off-peak 
hours to predict the increasing projected prices. In this way, we can formulate the first $\mathrm{OF}$ as follows:

$$
\begin{gathered}
\operatorname{Minf}_{1}(X)=\sum_{t=1}^{T} \operatorname{Cost}^{t}=\sum_{t=1}^{T}\left\{\sum_{i=1}^{N_{g}}\left[u_{i}(t) P_{G i}(t) B_{G i}(t)+S_{G i}\left|u_{i}(t)-u_{i}(t-1)\right|\right]+\right. \\
\sum_{i=1}^{N_{g}}\left[u_{j}(t) P_{s j}(t) B_{s j}(t)+S_{s j}\left|u_{j}(t)-u_{j}(t-1)\right|+P_{G r i d}(t) B_{G r i d}(t)\right\} .
\end{gathered}
$$

where $B_{G i}(t)$ represents the bids from the DG resources, $B_{s j}(t)$ is the storing options at hour $\mathrm{t}, S_{G i}$ is the start-up expenses for $i t h$ DG and $j$ th storage component, $S_{s j}$ gives the shut-down expenses for $i$ th DG and $j$ th storage component; $P_{\text {Grid }}(t)$ also represents the active power that is purchased/sold from/to the companies at time $t ; B_{\text {Grid }}(t)$ represents the bid of company at $t ; X$ also gives the vector of state variables such as active powers of power plants and their related states which can be defined as the following equations:

$$
\begin{aligned}
& \mathrm{X}=\left[\mathrm{P}_{\mathrm{g}}, \mathrm{U}_{\mathrm{g}}\right]_{1 \times 2 \mathrm{nT}} \\
& \mathrm{P}_{\mathrm{g}}=\left[\mathrm{P}_{\mathrm{G}}, \mathrm{P}_{\mathrm{s}}\right] \\
& \mathrm{n}=\mathrm{N}_{\mathrm{g}}+\mathrm{N}_{\mathrm{s}}+1
\end{aligned}
$$

where in the Equation (2), $T$ represents the total hours number in the tested time period; $n$ gives the state variables number; $N_{g}$ also represents the DGs' total number, and $N_{s}$ gives the storage total number of power plant units; $P_{g}$ represents the all DG units' active power; $U_{g}$ also gives the state vector defining the position of ON/OFF states for all power plant units in every hour of a day. All of these variables are given in Equations (3) and (4).

$$
\begin{aligned}
& P_{G}=\left[P_{G 1}, P_{G 2}, \ldots, P_{G, N_{g}}\right] \\
& P_{G i}=\left[P_{G i}(1), P_{G i}(2), \ldots, P_{G i}(t), \ldots, P_{G i}(T)\right] ; i=1,2, \ldots, N_{g}+1 \\
& P_{s}=\left[P_{s 1}, P_{s 2}, \ldots, P_{s, N_{s}}\right] \\
& P_{s j}=\left[P_{s j}(1), P_{s j}(2), \ldots, P_{s j}(t), \ldots, P_{s j}(T)\right] ; j=1,2, \ldots, N_{s}
\end{aligned}
$$

where in the Equation (3), $P_{G i}(t)$ and $P_{s j}(t)$ represent the outputs power for $i t h$ generator and $j$ th storage at time $t$.

$$
\begin{aligned}
& \mathrm{U}_{\mathrm{g}}=\left[\mathrm{u}_{1}, \mathrm{u}_{2}, \ldots, \mathrm{u}_{\mathrm{n}}\right]=\left\{\mathrm{u}_{\mathrm{i}}\right\}_{1 \times \mathrm{n}} \epsilon\{0,1\} ; \\
& \mathrm{u}_{\mathrm{k}}=\left[\mathrm{u}_{\mathrm{k}}(1), \mathrm{u}_{\mathrm{k}}(2), \ldots, \mathrm{u}_{\mathrm{k}}(\mathrm{t}), \ldots, \mathrm{u}_{\mathrm{k}}(\mathrm{T})\right] ; \mathrm{k}=1,2, \ldots, \mathrm{n}
\end{aligned}
$$

where $u_{k}(t)$ gives the unit status $k$ at hour $t$.

\subsubsection{Objective 2: Minimizing the Total Amount of Air Emissions in MG}

The environmental emissions impact of pollutants as the second objective should be considered in this study, where 3 of the most serious air pollutants in the optimization problem including carbon dioxide $\left(\mathrm{CO}_{2}\right)$, Sulphur dioxide $\left(\mathrm{SO}_{2}\right)$ and nitrogen oxides $\left(\mathrm{NO}_{x}\right)$ are involved [43]. In addition, logical functions which link air pollutants to the energy generation of various DGs are used to provide a model that illustrates such effects; similarly, it can be utilized for economic power dispatch. In this regard, the second OF will be given as Equation (5):

$$
\begin{gathered}
\operatorname{Min}_{2}(X)=\sum_{t=1}^{T} \text { Emission }^{t}=\sum_{t=1}^{T}\left\{\sum_{i=1}^{N_{g}}\left[u_{i}(t) P_{G i}(t) E_{G i}(t)\right]\right. \\
\left.+\sum_{i=1}^{N_{s}}\left[u_{j}(t) P_{s j}(t) E_{s j}(t)\right]+P_{\text {Grid }}(t) E_{G r i d}(t)\right\}
\end{gathered}
$$


where, $E_{G i}(t), E_{S i}(t)$, and $\left.E_{G r i d}(t)\right\}$ represent the level of air emissions in $\mathrm{kg} / \mathrm{MWh}$ for every distributed generation, storage module and the utility at hour $t$. All of variables are presented in the Equations (6) to (8):

$$
\mathrm{E}_{\mathrm{Gi}}(\mathrm{t})=\mathrm{CO}_{2 \mathrm{DG}_{\mathrm{i}}}+\mathrm{SO}_{2 \mathrm{DG}}(\mathrm{t})+\mathrm{NO}_{\mathrm{xDG}}(\mathrm{t})
$$

where, $C_{2 D G_{i}}$ is the amount of carbon dioxide, $S_{2 D G_{i}}(t)$ gives the amount of Sulphur dioxide, and $N O_{x D G_{i}}(t)$ represents the amount of emissions for nitrogen oxides from $i t h$ DG unit during hour $t$.

$$
\mathrm{E}_{\mathrm{sj}}(\mathrm{t})=\mathrm{CO}_{2 \text { ndorage }_{\mathrm{j}}}(\mathrm{t})+\mathrm{SO}_{2 \text { ndorage }_{\mathrm{j}}}(\mathrm{t})+\mathrm{NO}_{\mathrm{xSrorage}} \mathrm{j}_{\mathrm{j}}(\mathrm{t})
$$

where, $\mathrm{CO}_{2 \text { ndorage }}(t)$ is the amount of carbon dioxide, $\mathrm{SO}_{2 \text { ndorage }}(t)$ gives the amount of Sulphur dioxide, and $\mathrm{NO}_{x}(t)$ represents the number of emissions for nitrogen oxides from $j$ th storage unit at each hour of a day.

$$
\mathrm{E}_{\text {Grid }}(\mathrm{t})=\mathrm{CO}_{2 \text { Grid }}(\mathrm{t})+\mathrm{SO}_{2 \text { Grid }}(\mathrm{t})+\mathrm{NO}_{\mathrm{xGrid}}(\mathrm{t})
$$

where, $\mathrm{CO}_{2 \mathrm{Grid}}(t)$ is the amount of carbon dioxide, $\mathrm{SO}_{2 \mathrm{Grid}}(t)$ gives the amount of Sulphur dioxide, and $N O_{x \text { Grid }}(t)$ represents the number of emissions for $N O_{x}$ from the utility or the MG at hour $t$.

\subsection{Limitations}

\subsubsection{Load Balance}

In order to have an optimal energy management in energy system operational state, the principal limitation should be to satisfy loads with available power generations. Thus, the active power balancing condition for the MG should be formularized as follows:

$$
\sum_{i=1}^{N_{g}} P_{G i}(t)+\sum_{j=1}^{N_{s}} P_{s j}(t)+P_{\text {Grid }}(t)=\sum_{k=1}^{N_{k}} P_{L k}(t)
$$

where $P_{L k}$ gives the amount of $k t h$ load, also $N_{k}$ represents the load levels total number.

\subsubsection{Active Power Limitations of the Units}

The active power limitations of the power plant units are formulized as following equations:

$$
\begin{gathered}
\mathrm{P}_{\mathrm{Gi} \text { min }}(\mathrm{t}) \leq \mathrm{P}_{\mathrm{Gi}}(\mathrm{t}) \leq \mathrm{P}_{\mathrm{Gi}, \max }(\mathrm{t}) \\
\mathrm{P}_{\mathrm{si}, \min }(\mathrm{t}) \leq \mathrm{P}_{\mathrm{si}}(\mathrm{t}) \leq \mathrm{P}_{\mathrm{si}, \max }(\mathrm{t}) \\
\mathrm{P}_{\text {grid, min }}(\mathrm{t}) \leq \mathrm{P}_{\text {Grid }}(\mathrm{t}) \leq \mathrm{P}_{\text {grid, max }}(\mathrm{t})
\end{gathered}
$$

where in Equation (10), $P_{G, \min }(t)$ represents the minimum active powers of $i$ th DG, $P_{s, \min }(t)$ is the minimum active powers of $j t h$ storage, and $P_{\text {grid, } \min }(t)$ represents the minimum active powers of the utility, at time $t$. Similarly, $P_{G, \max }(t), P_{s, \max }(t)$, and $P_{\text {grid, } \max }(t)$ give the maximum energy generations of corresponding units during hour $t$.

\subsubsection{Charge and Discharge Level Constrains of Storage System Modules}

Owing to constrain of the charge and discharge level of storing systems at every time interval, the formulations and limitations need to be considered as follows:

$$
\begin{gathered}
W_{\text {ess }, \mathrm{t}}=W_{\text {ess }, \mathrm{t}-1}+\eta_{\text {charge }} P_{\text {charge }} \Delta t-\frac{1}{\eta_{\text {discharge }}} P_{\text {discharge }} \Delta t \\
\left\{\begin{array}{c}
W_{\text {ess,min }} \leq W_{\text {ess }, \mathrm{t}} \leq W_{\text {ess, max }} \\
P_{\text {charge, } t} \leq P_{\text {charge, max }} ; \quad P_{\text {discharge, },} \leq P_{\text {discharge, max }}
\end{array}\right.
\end{gathered}
$$


where, $W_{e s s, t}$ and $W_{e s s, t-1}$ represent the amounts of power in battery storage system at hour $t$ and hour $t-1$, respectively; also $P_{\text {charge }}$ and $P_{\text {discharge }}$ give the levels of permitted charge and discharge via a definite time period $\Delta t$. $\eta_{\text {charge }}$ and $\eta_{\text {discharge }}$ indicate the efficiency of the charge/discharge in the battery storage system. $W_{e s s, \min }$ and $W_{\text {ess, max }}$ represent the minimum and maximum constraints of battery storage system while $P_{\text {charge, } \max }$ and $P_{\text {discharge, max }}$ give the maximum levels of charge or discharge state in every interval $\Delta t$.

\subsection{MG Modeling}

Since using DGs can have different effects on power system characteristics, application and modelling of DGs can cause various issues. One possible solution to maximize the benefits of using DGs is to have an effective method to optimally model the generation of relevant power and loads in the network as a subsystem in a form of MG. Additionally, by integrating DGs into a MG and using RESs in large quantities, issues related to the optimization of cost and environmental pollutants reduction can be investigated in the targeted system. Such strategies can make appropriate decisions to a better energy management and enhance the performance of operation.

In addition, using DGs in forms of RESs such as fossil fuel engines, gas and micro turbines (MTs), photovoltaics (PVs) and fuel cells (FCs), and wind turbine (WT) in MG needs higher and complicated technologies, which can significantly lower emissions and air pollution. For instance, FCs which generate power from oxygen and hydrogen are emitting only vapor. However, at the same time of modification of natural gas, various forms of $\mathrm{NO}_{x}$ and $\mathrm{CO}_{2}$ air pollutants are emitted. Another example could be the use of MTs with lower emissions; however, currently they are more expensive.

In this research work, a typical low-voltage (LV) smart-MG is considered which is shown in Figure 1 consisting of different DGs including MTs, FCs, PVs, WT, and storage system devices (batteries).

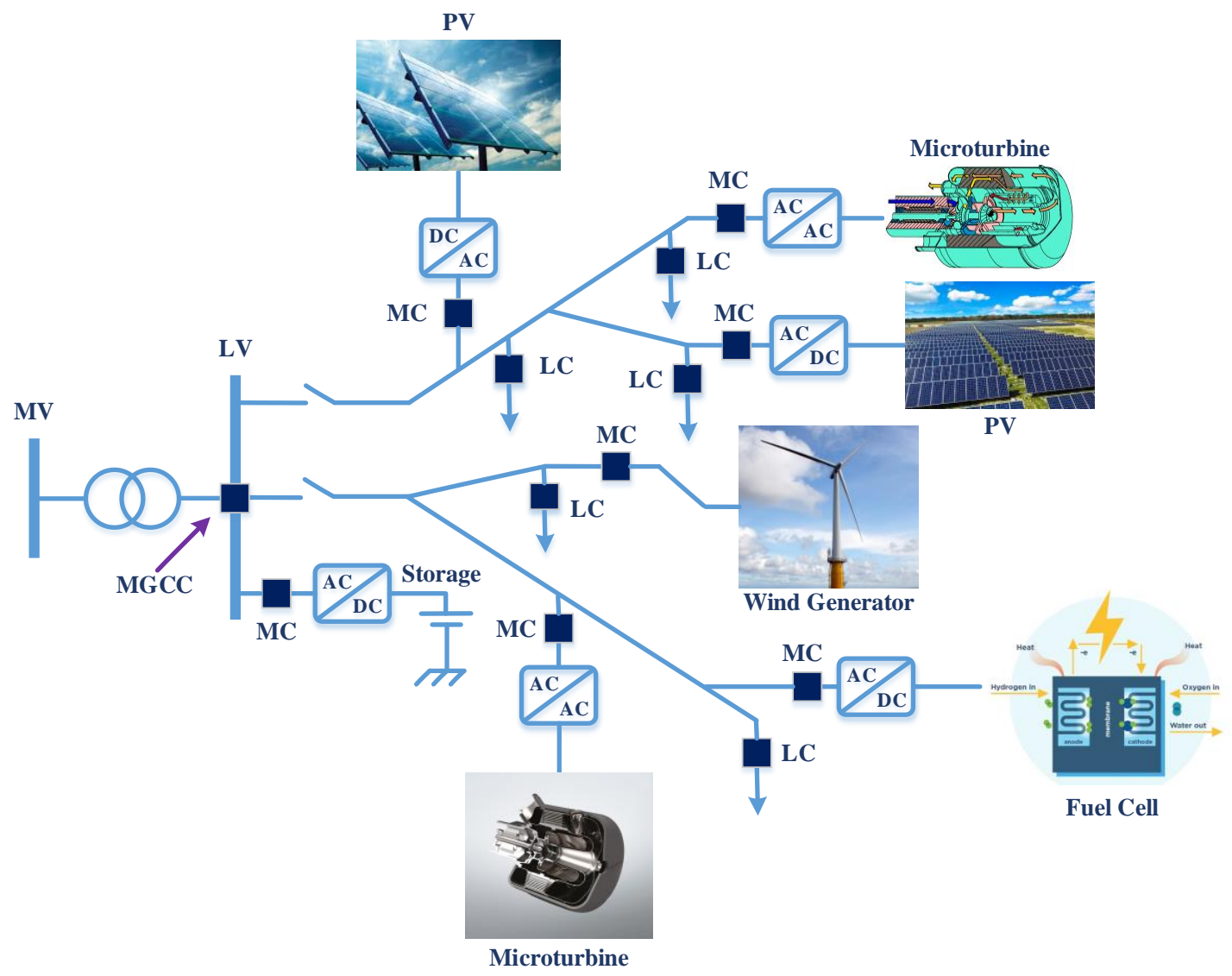

Figure 1. A typical LV-MG model. 
In this regard, it is presumed that all DG resources generate active power at the power factor one, without any requesting or generating reactive power. In addition, there is a link for power exchange from the presented MG and the grid utilized for power trading in various hours of a day according to decisions of MG control center (MGCC).

\subsection{Principles of IDE Algorithm and Multi-Objective Optimization}

In general, real-world optimization issues involve various goals that should be optimized simultaneously, and this set of goals might have conflicting and different goals and incomparable applications $[44,45]$. In order to simultaneously address these issues towards optimal aims, multi-objective optimization techniques can be used effectively to obtain a set of optimal answers. In this section, the principles of our proposed IDE algorithm to optimize energy management in MG are presented; hence, we need to present Equation (13):

$$
\begin{gathered}
\text { Minimize } F=\left[\mathrm{f}_{1}(\mathrm{X}), \mathrm{f}_{2}(\mathrm{X}), \ldots, \mathrm{f}_{\mathrm{m}}(\mathrm{X})\right]^{\mathrm{T}} \\
\text { Subject to : }\left\{\begin{array}{cc}
\mathrm{g}_{\mathrm{i}}(\mathrm{X})<0 & i=1,2, \ldots, \mathrm{N}_{\mathrm{ueq}} \\
\mathrm{h}_{\mathrm{i}}(\mathrm{X})=0 & i=1,2, \ldots, \mathrm{N}_{\mathrm{eq}}
\end{array}\right. \text {. }
\end{gathered}
$$

In Equation (13), $F$ gives the objective functions vector, and $X$ represents the optimization variables vector, $f_{i}(X)$ also represents the $i t h$ objective function, $g_{i}(X)$ is the equality constraint and $h_{i}(X)$ represents inequality constraints; $m$ also gives the number of objective functions.

\subsubsection{Differential Evolutionary Algorithm}

DE algorithm, today, acts one of the highly efficient alternatives to optimize complicated multi-objective issues. DE algorithm dives a fast rate of convergence, robustness with a global optimization capability. To generate the vectors of trial parameter, the principle operation of this algorithm consists of the mutation, crossover, and selection operations. The principal operating process of the basic DE has been provided in reference [46]. Of all the operational above-mentioned items, mutation operation can act as the core of DE algorithm. Several and various mutations mechanisms have been presented in the literature review and the frequently utilized five different techniques which are listed in the following equations:

$\mathrm{DE} / \mathrm{rand} / 1$ :

$$
\mathrm{v}_{\mathrm{i}}^{\mathrm{t}}=\mathrm{x}_{\mathrm{r}_{1}}^{\mathrm{t}}+\mathrm{F} \times\left(\mathrm{x}_{\mathrm{r}_{2}}^{\mathrm{t}}-\mathrm{x}_{\mathrm{r}_{3}}^{\mathrm{t}}\right)
$$

$\mathrm{DE} / \mathrm{rand} / 2$ :

$$
\mathrm{v}_{\mathrm{i}}^{\mathrm{t}}=\mathrm{x}_{\mathrm{r}_{1}}^{\mathrm{t}}+\mathrm{F} \times\left[\left(\mathrm{x}_{\mathrm{r}_{2}}^{\mathrm{t}}-\mathrm{x}_{\mathrm{r}_{3}}^{\mathrm{t}}\right)+\left(\mathrm{x}_{\mathrm{r}_{4}}^{\mathrm{t}}-\mathrm{x}_{\mathrm{r}_{5}}^{\mathrm{t}}\right)\right]
$$

$\mathrm{DE} /$ best/1:

$$
\mathrm{v}_{\mathrm{i}}^{\mathrm{t}}=\mathrm{x}_{\text {best }}^{\mathrm{t}}+\mathrm{F} \times\left(\mathrm{x}_{\mathrm{r}_{1}}^{\mathrm{t}}-\mathrm{x}_{\mathrm{r}_{2}}^{\mathrm{t}}\right)
$$

$\mathrm{DE} /$ best/2:

$$
\mathrm{v}_{\mathrm{i}}^{\mathrm{t}}=\mathrm{x}_{\text {best }}^{\mathrm{t}}+\mathrm{F} \times\left[\left(\mathrm{x}_{\mathrm{r}_{1}}^{\mathrm{t}}-\mathrm{x}_{\mathrm{r}_{2}}^{\mathrm{t}}\right)+\left(\mathrm{x}_{\mathrm{r}_{3}}^{\mathrm{t}}-\mathrm{x}_{\mathrm{r}_{4}}^{\mathrm{t}}\right)\right]
$$

$\mathrm{DE} /$ current to best/1:

$$
\mathrm{v}_{\mathrm{i}}^{\mathrm{t}}=\mathrm{x}_{\text {best }}^{\mathrm{t}}+\mathrm{F} \times\left[\left(\mathrm{x}_{\text {best }}^{\mathrm{t}}-\mathrm{x}_{\mathrm{i}}^{\mathrm{t}}\right)+\left(\mathrm{x}_{\mathrm{r}_{1}}^{\mathrm{t}}-\mathrm{x}_{\mathrm{r}_{2}}^{\mathrm{t}}\right)\right]
$$

where, $t=1,2,3, \ldots$ represents the generation (time), indices $r_{i}(i=1,2, \ldots, 5)$ give the mutually exclusive integers which generated randomly through $[1, N P]$, that differ from index $i ; x_{b s e t}^{t}$ represents the best vector that denotes the best amount of fitness of the population in generation $t$; also $F$ gives the scale factor. The crossover operation also consists of the binomial crossover approach and the index cross approach. The most 
commonly utilized bi-nominal crossover operation has been used in this research work. Hence, we should define the following equation as:

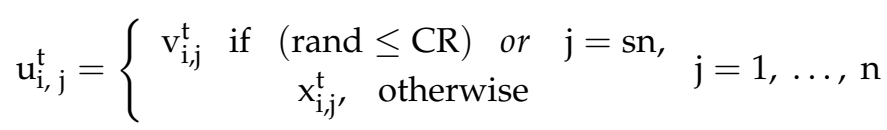

where $s n \in[1, n]$ represents a random integer; $u_{i, j}^{t}$ gives the $j$ th part of the $i$ th new trail vector, also $C R$ denotes the rate of crossover through the range $[0,1]$. In addition, if the experimental vector performs better than the target vector, in the next generation, the experimental vector will be replaced by the greedy selection vector in the selection operation with the target vector.

$$
x_{i}^{t+1}=\left\{\begin{array}{c}
u_{i}^{t} \text { if }\left(f\left(u_{i}^{t}\right) \leq f\left(x_{i}^{t}\right)\right) \\
x_{i}^{t}, \text { otherwise }
\end{array}\right.
$$

In the proposed strategy, the degree of solution limitation violation $x$ on the $j$ th limit can be obtained using Equation (21).

$$
G_{j}(x)=\left\{\begin{array}{cc}
\max \left\{g_{i}(x), 0\right\}, & j=1,2, \ldots, p, \\
\max \left\{\left|h_{i}(x)\right|, 0\right\} & j=P+1, \ldots, q
\end{array}\right.
$$

The general limitation degree of solution $x$ can be computed using Equation (22).

$$
\varnothing(\mathrm{x})=\sum_{\mathrm{j}=1}^{\mathrm{q}} \mathrm{G}_{\mathrm{j}}(\mathrm{x})
$$

\subsubsection{Improved Self-Adaptive Differential Evolutionary Algorithm}

In this section, the proposed improved IDE has been introduced and the adaption mechanism has been described.

Adaptive Regulation Mechanisms for Scale Factor and Crossover Rate

Selecting $F$ and $C R$ depends highly on the specified issue that was applied, and that is almost difficult. Overall, small values of $F$ and $C R$ lead to a faster convergence speed, whereas large values of $F$ and $C R$ contribute to rise the population diversity and can prevent premature convergence. In order to obtain a balance from the speed of convergence to premature convergence, having an adaptive regulation mechanism for $F$ and $C R$ will be essential. So, to develop the global searching ability with escaping the local optimal and preventing the premature convergence, an improved approach and technique is proposed to develop the total efficiency of the IMODE algorithm in this research. In the proposed algorithm, a heuristic searching optimization approach according to the basics of genetics and immune adaptive (IA) method is proposed. During the process of population search, IA maintains the potential solutions populations. As a result, in order to reach the parameters of the optimal scale factor, the principles of immune approach are used. The strategies of parameter $\mathrm{F}$ for updating are adjusted as the following steps:

1. Computing values of affinity: IA utilizes the affinity as a differentiator between the qualities of solutions; besides, antibodies with a higher affinity are more likely to be opted, and at the higher probability, are more likely to be surviving for the next generation. Hence, we describe the affinity in Equation (23).

$$
\text { affinity }_{\mathrm{i}, \mathrm{t}}=\mathrm{r} \times(1-\mathrm{r})^{\mathrm{i}-1}
$$


where, the coefficient $r \in[0,0.5] ; i$ also by arranging them based on their performance values, shows the numerical order of every antibody in the population. In order to calculate the values of affinity for the parameters of scale factor, we define Equation (24) as follows:

$$
\mathrm{A}_{\left(\mathrm{F}_{\mathrm{i}}\right)}=\left\{\begin{array}{c}
\left|\frac{\mathrm{f}\left(\mathrm{x}_{\mathrm{i}}^{\mathrm{t}}-\mathrm{f}\left(\mathrm{x}_{\mathrm{i}}^{\mathrm{t}+1}\right)\right)}{\mathrm{f}\left(\mathrm{x}_{\mathrm{i}}^{\mathrm{T}+1}\right)}\right|, f\left(\mathrm{x}_{\mathrm{i}}^{\mathrm{t}+1}\right)<f\left(\mathrm{x}_{\mathrm{i}}^{\mathrm{t}}\right) \\
0, \text { otherwise }
\end{array}\right.
$$

Based on their affinity, the parameters of scale factor should be arranged between the best and the worst, where the best twenty percent mutation parameters $M F^{T+1}$ (new) have been stored in the memory based on MF.

2. Updating the MF memory based on MF:

$$
M P_{j}^{T+1}=\left\{\begin{array}{c}
M F_{j+\alpha N^{\prime}}^{T}, j \leq N-\alpha N \\
M F_{j+\alpha N-N^{\prime}}^{T+1}(\text { new }), \text { otherwise }
\end{array}\right.
$$

3. Generating the scale factor parameters for the next generation. Now, the scale factor parameters in the next generation should be updated as follows:

$$
\mathrm{F}_{j}^{\mathrm{T}+1}=\left\{\begin{array}{l}
\mathrm{MF}_{\mathrm{j}}^{\mathrm{T}+1}, \mathrm{P}_{\mathrm{i}} \leq \mathrm{P}_{\mathrm{F}} \\
\widetilde{\mathrm{F}}_{\mathrm{j}}^{\mathrm{T}+1}, \text { otherwise }
\end{array}\right.
$$

where the initial $F_{j}^{T+1}$ has been generated by a normal distribution $N(0.5,1)$ through $[0,1]^{2}, P_{i}$ represents a random number in the distance within $[0,1]$, and $P_{F}$ represents the regulating probability. Considering these items and based on the reference [47], the crossover rate $(C R)$ values have been updated as:

$$
\mathrm{CR}_{\mathrm{i}}^{\mathrm{t}+1}= \begin{cases}\underset{\mathrm{rand}}{3}, & \text { if } \\ \mathrm{CR}_{\mathrm{i}}^{\mathrm{t}}, & \operatorname{rand}_{4}<\tau \\ \text { otherwise }\end{cases}
$$

where, $\tau=0.9$ represents the adjusting probability in our proposed method.

\section{Limitation-Handling Technique}

Because optimization issues in the real-world are often connected to various limitations, the alpha $(\alpha)$-finite approach has been utilized to address limitations. The $\alpha$-finite technique treats several infeasible solutions as feasible approaches whenever such nonapplicable solutions are under a specific level. In order to control the level $\alpha$, Equation (28) is presented.

$$
\begin{gathered}
\alpha(0)=\varnothing\left(\mathrm{x}_{\theta}\right) \\
\alpha(\mathrm{t})=\left\{\begin{array}{cc}
\alpha(0)\left(1-\frac{\mathrm{t}}{\mathrm{T}_{\mathrm{c}}}\right)^{\mathrm{cp}}, & 0<t<\mathrm{T}_{\mathrm{c}} \\
0, & t \geq \mathrm{T}_{\mathrm{c}}
\end{array}\right.
\end{gathered}
$$

where $x_{\theta}$ represents the top $\theta$ th solution at the initialization phase; $c p$ denotes a parameter for controlling the speed of limitations reducing relaxation; $\theta$ has been suggested to be $0.2 * N P$; also $c p \in[2,10]$. For having an efficiently using of the information performed by the infeasible solutions, the concept of pseudo feasible has been described. Generally, the pseudo feasible solution gives the overall solution whose general limit violation becomes less than $\alpha$. A detailed study about the limited-dominate connection between individuals consisting of pseudo feasible and pseudo infeasible solutions has been presented in the reference [48]. After the phase of sorting operation based on the limited-dominate connection criteria, exactly NP solutions should be selected from combined population $X^{t} \cup U^{t}$ to new population $X^{t+1}$. By combining the self-adaptive evolutionary method and immune operation, the step by step pseudo code of the new improved self-adaptive evolutionary is presented as below: 
Step 1: $\quad$ Set the parameters' values and initialize the external archive.

Step 2: $\quad$ Set the generation number $G=0$ randomly initialize a population of NP individuals

uniformly distributed in the range $\left[X_{\min }, X_{\max }\right]$

Step 3: $\quad$ Evaluate the fitness of initial solutions

Step 4: WHILE the termination criterion is not satisfied, DO

Step 4.1: Generating offspring solutions by DE's trial vector generation operators

Step 4.1.1: $\quad$ Mutation step

FOR $\mathrm{i}=1$ to NP

Generate a mutated vector according to the self-adaptive mutation strategy

END FOR

Step 4.1.2: Crossover step

FOR i $=1$ to NP

Generate a trial vector for each target vector using binomial crossover operator.

END FOR

Divide the combination of parent and offspring population into two subpopulations

Step 5: $\quad$ according to pseudo feasible concept, SubP1 (pseudo feasible solutions) and SubP2 (pseudo infeasible solutions)

Step 5.1: $\quad$ Order the SubP1 by non-dominated sorting procedure

Step 5.2: $\quad$ Order the SubP2 according to overall violation degree

Step 6: Add all the non-dominated solutions into external archive and remove the inferior

ones.

Step 7: $\quad$ Select solutions for the main population of the next generation

Step 8: $\quad$ Update the parameters

Step 9: $\quad$ Increment the generation count $G=G+1$.

END WHILE

All simulations are performed in a typical system that has MT resources, PVs, WTs, FCs, ES units with having the capability of upstream grid power exchange.

\section{Simulation Results}

For demonstrating the efficiency of the IDE algorithm in solving the problem of optimal operation of the MG in both single-objective and multi-objective modes, this algorithm has been performed on different problems. First, it is assumed that there is no limit to the exchange of power overhead, and secondly, the limitation of power exchange with the upstream grid is considered. In multi-objective mode, these two modes are also considered. In order to illustrate the impact of RE generations on the cost, in the third part of the simulations, the operation is solved with maximum participation of renewable energy sources. In the final section, the sensitivity analysis on the number of populations in this problem is performed. The figures for gas emissions of resources, costs, and minimum and maximum production are available in Table 1 . The rate of daily loading is available in Table 2. Additionally, Table 3 shows the market price for upstream power exchange. Forecasts for photovoltaic and wind turbine sources are available, and their maximum output is given in Table 4 . The cost coefficients $(\$ / \mathrm{kWh})$ and emissions $(\mathrm{kg} / \mathrm{MWh})$ assumed by the DG resources are shown in Table 1.

Table 1. The figures for gas emissions of resources, costs, and minimum and maximum production.

\begin{tabular}{|c|c|c|c|c|c|c|}
\hline Kind of Resource & $\begin{array}{c}\text { NOx } \\
\text { (kg/Mwh) }\end{array}$ & $\begin{array}{c}\text { NOx } \\
\text { (kg/Mwh) }\end{array}$ & $\begin{array}{c}\mathrm{CO}_{2} \\
\text { (kg/Mwh) }\end{array}$ & $\begin{array}{c}\text { Cost } \\
(\$ / K w h)\end{array}$ & $\begin{array}{c}\text { Maximum } \\
\text { Power (Kw) }\end{array}$ & $\begin{array}{c}\text { Minimum Power } \\
(\mathrm{Kw})\end{array}$ \\
\hline Micro Turbine & 0.1 & 0.1 & 720 & 0.457 & 30 & 6 \\
\hline Fuel Cell & 0.0075 & 0.0075 & 460 & 0.294 & 30 & 3 \\
\hline Photovoltaic & 0 & 0 & 0 & 2.584 & 25 & 0 \\
\hline Wind Turbine & 0 & 0 & 0 & 1.073 & 15 & 0 \\
\hline Battery & 0.001 & 0.001 & 10 & 0.38 & 30 & $30-$ \\
\hline Upstream Grid & 0 & 0 & 0 & According to Table 3 & 30 & 30- \\
\hline
\end{tabular}


Table 2. Rate of daily loading.

\begin{tabular}{ccccccc}
\hline Hour & $\mathbf{1}$ & $\mathbf{2}$ & $\mathbf{3}$ & $\mathbf{4}$ & $\mathbf{5}$ & $\mathbf{6}$ \\
\hline Load $(\mathrm{Kw})$ & 52 & 50 & 50 & 51 & 57 & 62 \\
Hour & 7 & 8 & 9 & 10 & 11 & 12 \\
Load $(\mathrm{Kw})$ & 70 & 74 & 76 & 79 & 78 & 75 \\
Hour & 13 & 14 & 15 & 16 & 17 & 18 \\
Load $(\mathrm{Kw})$ & 72 & 71 & 76 & 80 & 85 & 87 \\
Hour & 19 & 20 & 21 & 22 & 23 & 24 \\
Load $(\mathrm{Kw})$ & 90 & 87 & 77 & 71 & 65 & 58 \\
\hline
\end{tabular}

Table 3. Market price for upstream power exchange.

\begin{tabular}{ccccccc}
\hline Hour & $\mathbf{1}$ & $\mathbf{2}$ & $\mathbf{3}$ & $\mathbf{4}$ & $\mathbf{5}$ & $\mathbf{6}$ \\
\hline Price $(\$)$ & 0.23 & 0.19 & 0.14 & 0.12 & 0.12 & 0.20 \\
Hour & 7 & 8 & 9 & 10 & 11 & 12 \\
Price $(\$)$ & 0.23 & 0.38 & 1.5 & 4 & 4 & 4 \\
Hour & 13 & 14 & 15 & 16 & 17 & 18 \\
Price $(\$)$ & 1.5 & 4 & 2 & 21.95 & 6 & 0.41 \\
Hour & 19 & 20 & 21 & 0.54 & 0.30 & 24 \\
Price $(\$)$ & 0.35 & 0.43 & 1.17 & & & 0.26 \\
\hline
\end{tabular}

Table 4. Production rate of wind turbine and photovoltaic per one unit of production.

\begin{tabular}{ccccccc}
\hline Hour & $\mathbf{1}$ & $\mathbf{2}$ & $\mathbf{3}$ & $\mathbf{4}$ & $\mathbf{5}$ & $\mathbf{6}$ \\
\hline WT $(\mathrm{kW}) /$ installed $(\mathrm{kW})$ & 0.1190 & 0.1190 & 0.1190 & 0.1190 & 0.1190 & 0.0610 \\
PV $(\mathrm{kW}) /$ installed $(\mathrm{kW})$ & 0.00 & 0.00 & 0.00 & 0.00 & 0.00 & 0.00 \\
Hour & 7 & 8 & 9 & 10 & 11 & 12 \\
WT $(\mathrm{kW}) /$ installed $(\mathrm{kW})$ & 0.1190 & 0.0870 & 0.1190 & 0.2060 & 0.5850 & 0.6940 \\
PV $(\mathrm{kW}) /$ installed $(\mathrm{kW})$ & 0.00 & 0.0080 & 0.1500 & 0.3010 & 0.4180 & 0.4780 \\
Hour & 13 & 14 & 15 & 16 & 17 & 18 \\
WT $(\mathrm{kW}) /$ installed $(\mathrm{kW})$ & 0.2610 & 0.1580 & 0.1190 & 0.0870 & 0.1190 & 0.1190 \\
PV $(\mathrm{kW}) /$ installed $(\mathrm{kW})$ & 0.9560 & 0.8420 & 0.3150 & 0.1690 & 0.0220 & 0.00 \\
Hour & 19 & 20 & 21 & 22 & 23 & 24 \\
WT $(\mathrm{kW}) /$ installed $(\mathrm{kW})$ & 0.0867 & 0.1190 & 0.0867 & 0.0867 & 0.0610 & 0.0410 \\
PV $(\mathrm{kW}) /$ installed $(\mathrm{kW})$ & 0.00 & 0.00 & 0.00 & 0.00 & 0.00 & 0.00 \\
\hline
\end{tabular}

\subsection{Single Objective Optimization}

\subsubsection{Without Considering the Limitations of Power Exchange with Upstream Grid}

For solving the single-objective problem in the unlimited power exchange mode with the network, both cost and pollution (gas emission) targets have been studied separately. The results are compared with the PSO and DE methods and the convergence diagrams are presented in Figures 2 and 3. Both forms show better convergence of the IDE algorithm compared to the other methods. Table 5 to Table 6 illustrate how to distribute power to reduce costs and gas emission without considering the limitations of upstream network power exchange with two objectives. The last column of the tables illustrates the unlimited power exchange with the upstream utility grid. Tables 7 and 8 show the results of 10 consecutive runs of each method. The proposed algorithm is better than all other methods in all the best, worst, and average of the indices, and therefore, the superiority in both targets is quite clear. 
Table 5. Distributing power to reduce costs without considering the limitations of upstream network power exchange.

\begin{tabular}{ccccccc}
\hline \multirow{2}{*}{ Time } & MT (kW) & FC (kW) & PV (kW) & WT (kW) & Storage (kW) & Grid (kW) \\
\hline 1 & 6 & 3 & 0 & 0 & -10 & 53 \\
2 & 6.01 & 3 & 0 & 0 & 10 & 31 \\
3 & 6 & 3.03 & 0 & 0 & -10 & 50.87 \\
4 & 6 & 3 & 0 & 0.05 & 10 & 31.93 \\
5 & 6 & 3.02 & 0 & 0 & -10 & 57.97 \\
6 & 6 & 3 & 0 & 0 & 10 & 42.99 \\
7 & 6 & 30 & 0 & 0.14 & -10 & 43.86 \\
8 & 6 & 30 & 0.16 & 0.03 & 0.11 & 37.66 \\
9 & 30 & 30 & 0 & 1.43 & -0.1 & 14.88 \\
10 & 30 & 30 & 6.02 & 2.47 & 9.98 & 0.54 \\
11 & 30 & 30 & 8.36 & 7.02 & 10 & -7.38 \\
12 & 30 & 30 & 9.56 & 8.33 & 10 & -12.89 \\
13 & 30 & 30 & 0 & 3.13 & -10 & 18.87 \\
14 & 30 & 30 & 16.84 & 1.9 & 10 & -17.74 \\
15 & 30 & 30 & 0 & 0 & 10 & 6 \\
16 & 29.98 & 30 & 0 & 0 & -0.55 & 22.42 \\
17 & 30 & 30 & 0 & 0 & 0 & 25.22 \\
18 & 30 & 30 & 0 & 0 & -7.71 & 31.99 \\
19 & 6 & 29.99 & 0 & 0 & -10 & 64.01 \\
20 & 6 & 30 & 0 & 0 & -3.37 & 57.94 \\
21 & 30 & 30 & 0 & 1.04 & 10 & 5.96 \\
22 & 30 & 29.93 & 0 & 0 & 9.99 & 1.1 \\
23 & 6 & 30 & 0 & 0 & -10 & 38.99 \\
24 & 6 & 3 & 0 & 0.48 & -10 & 58.51 \\
\hline & & 30 & & & &
\end{tabular}

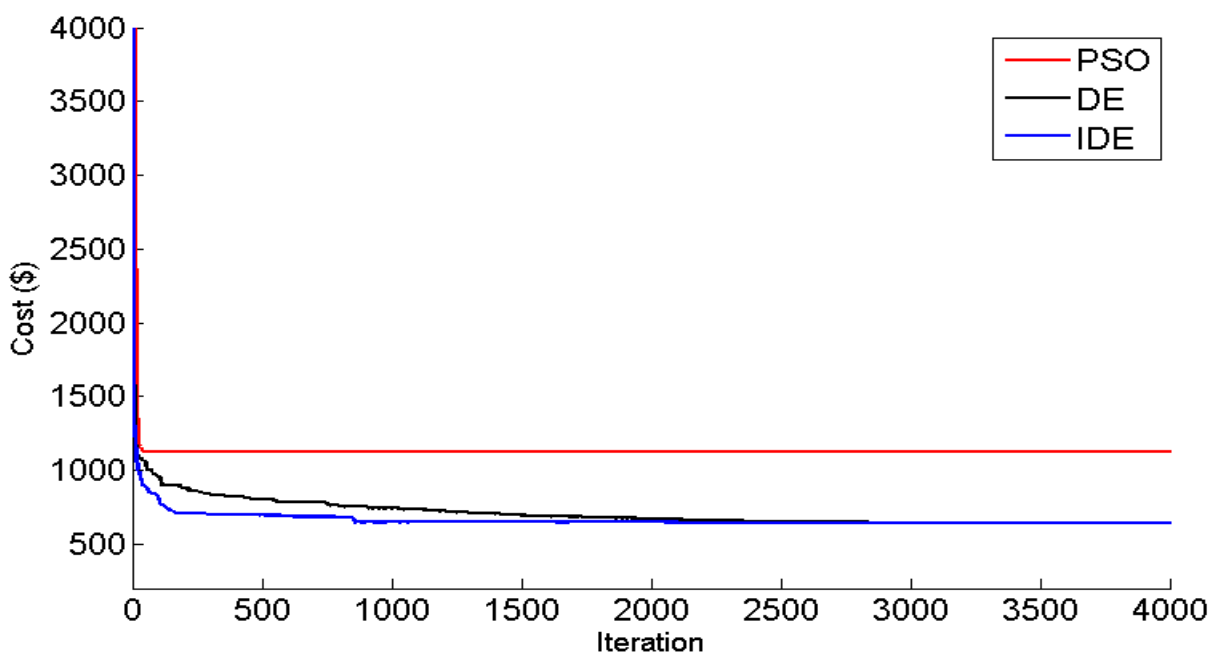

Figure 2. Cost convergence diagram in different methods without considering the limitations of power exchange with upstream network. 


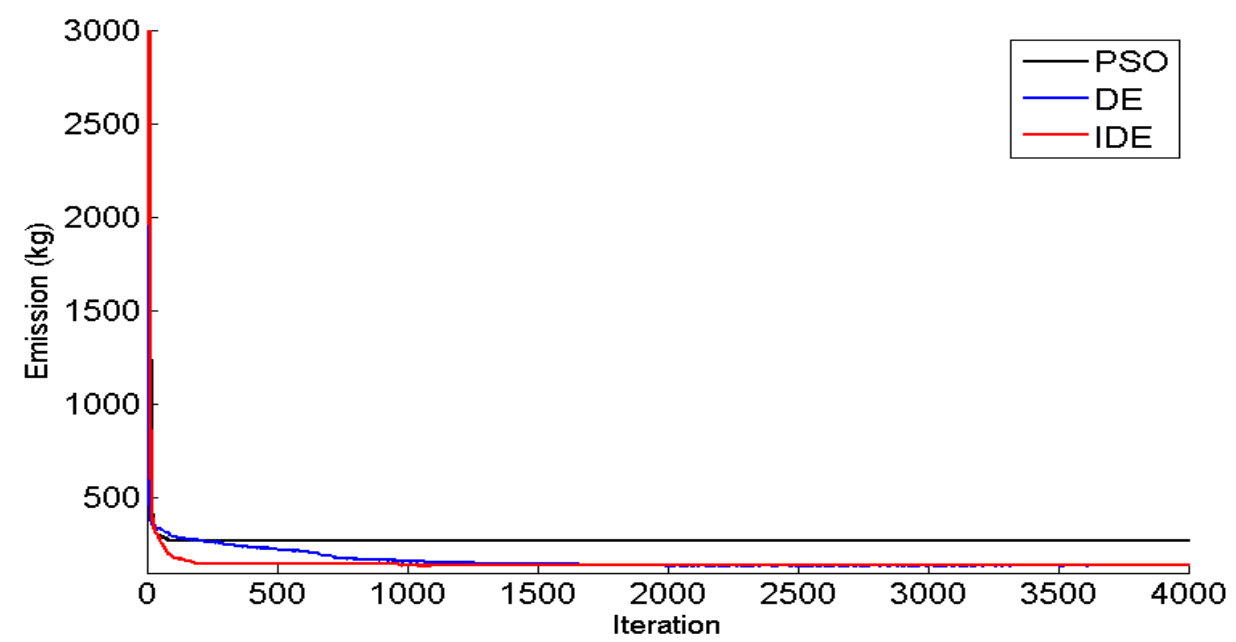

Figure 3. Convergence diagram of emission in different methods without considering the limitations of upstream power exchange.

Table 6. Distributing power to reduce pollution without considering the limitation of upstream exchange.

\begin{tabular}{ccccccc}
\hline \multirow{2}{*}{ Time } & MT (kW) & FC (kW) & PV (kW) & WT (kW) & Storage (kW) & Grid (kW) \\
\hline 1 & 6 & 3 & 0 & 1.43 & -9.88 & 51.32 \\
2 & 6 & 3.03 & 0 & 0 & 5.3 & 31.7 \\
3 & 6 & 3 & 0 & 1.43 & 10 & 29.57 \\
4 & 6 & 3 & 0 & 1.43 & 10 & 30.58 \\
5 & 6 & 3 & 0 & 1.43 & -10 & 56.57 \\
6 & 6 & 3 & 0 & 0.25 & 10 & 43 \\
7 & 6 & 3 & 0 & 0.14 & -9.99 & 70.82 \\
8 & 6 & 3 & 0.16 & 0.98 & -10 & 73.91 \\
9 & 6 & 3 & 3 & 0 & 10 & 54 \\
10 & 6 & 3 & 6.02 & 0.02 & 10 & 53.95 \\
11 & 6 & 3 & 8.36 & 7.02 & -8.65 & 61.32 \\
12 & 6 & 3.02 & 9.56 & 8.33 & 10 & 38.09 \\
13 & 6 & 3 & 0 & 3.13 & -10 & 69.87 \\
14 & 6 & 3 & 16.84 & 0 & 10 & 35.16 \\
15 & 6 & 3 & 6.3 & 1.43 & -10 & 69.27 \\
16 & 6 & 3 & 3.31 & 1.04 & 10 & 56.69 \\
17 & 6 & 3 & 0.44 & 1.43 & -10 & 84.13 \\
18 & 6 & 3 & 0 & 1.43 & 4.74 & 74.42 \\
19 & 6 & 3 & 0 & 1.04 & -10 & 89.96 \\
20 & 6 & 3 & 0 & 0 & -10 & 88 \\
21 & 6 & 3 & 0 & 0 & 9.97 & 58.08 \\
22 & 6 & 3 & 0 & 1.04 & -10 & 70.96 \\
23 & 6 & 3.01 & 0 & 0.73 & 10 & 45.25 \\
24 & 6 & 3 & 0 & 0 & -9.97 & 58.94 \\
\hline
\end{tabular}

Table 7. Comparison of the proposed method with other methods for reducing costs without considering the limitations of upstream network power exchange.

\begin{tabular}{ccccc}
\hline Method & $\begin{array}{c}\text { Best Answers } \\
\mathbf{( \$ )}\end{array}$ & $\begin{array}{c}\text { Average } \\
\text { Answers (\$) }\end{array}$ & $\begin{array}{c}\text { Worst Answers } \\
\mathbf{( \$ )}\end{array}$ & $\begin{array}{c}\text { Standard } \\
\text { Deviation (\$) }\end{array}$ \\
\hline PSO & 882.48 & 1006.81 & 1140.77 & 91.61 \\
DE & 631.18 & 651.7 & 664.78 & 12.08 \\
IDE & 618.91 & 651.28 & 768.84 & 45.22 \\
\hline
\end{tabular}


Table 8. Comparison of the proposed method with other methods for reducing gas emission without considering the limitations of upstream network power exchange.

\begin{tabular}{ccccc}
\hline Method & $\begin{array}{c}\text { Best Answers } \\
\mathbf{( k g )}\end{array}$ & $\begin{array}{c}\text { Average } \\
\text { Answers (kg) }\end{array}$ & $\begin{array}{c}\text { Worst Answers } \\
\mathbf{( k g )}\end{array}$ & $\begin{array}{c}\text { Standard } \\
\text { Deviation } \mathbf{( k g )}\end{array}$ \\
\hline PSO & 178.73 & 373.61 & 1297.41 & 327.62 \\
DE & 136.7 & 152.35 & 178.77 & 16.17 \\
IDE & 136.49 & 151.3 & 171.17 & 16.07 \\
\hline
\end{tabular}

\subsubsection{With Considering the Limitations of Power Exchange with Upstream Network}

In this section, the power exchange with the utility grid is considered as finite. The distributions of power for different purposes are provided in Tables 9 and 10. Comparison of the results of the cost and pollution targets in both cases with and without network limitation shows that considering the power exchange constraint with the network increases the cost and pollution. A comparison is also made between the proposed method and the methods of PSO and DE and the results are shown in Figures 4 and 5 as well as Tables 11 and 12 . The results indicate the superiority of the proposed method over other methods.

Table 9. Power distribution for reducing costs and considering the limitations of the upstream network exchange.

\begin{tabular}{ccccccc}
\hline \multirow{2}{*}{ Time } & MT (kW) & FC (kW) & PV (kW) & WT (kW) & Storage (kW) & Grid (kW) \\
\hline 1 & 6.01 & 15.03 & 0 & 0 & 2.64 & 27.93 \\
2 & 7.44 & 4.6 & 0 & 1.41 & 9.9 & 27.57 \\
3 & 17.22 & 4.76 & 0 & 0.1 & -0.73 & 24.11 \\
4 & 19.8 & 4.29 & 0 & 0 & -1.35 & 25.95 \\
5 & 17.2 & 11.59 & 0 & 0.32 & -1.08 & 28.44 \\
6 & 29.98 & 3 & 0 & 0.17 & 3.22 & 20.2 \\
7 & 29.91 & 29.99 & 0 & 0.02 & -7.07 & 15.61 \\
8 & 17.17 & 29.53 & 0.03 & 0.08 & -2.76 & 29.31 \\
9 & 29.65 & 29.97 & 0.02 & 1.4 & -0.04 & 14.71 \\
10 & 29.91 & 30 & 5.92 & 2.27 & 9.95 & 1.66 \\
11 & 29.83 & 29.99 & 8.33 & 7.02 & 7.03 & -5.44 \\
12 & 29.89 & 30 & 9.51 & 8.3 & 10 & -12.65 \\
13 & 29.27 & 29.98 & 0.07 & 2.69 & 2.71 & 9.6 \\
14 & 29.97 & 29.96 & 16.84 & 0.25 & 9.97 & -15.93 \\
15 & 29.98 & 29.9 & 0.13 & 0.78 & -3.54 & 18.27 \\
16 & 29.59 & 29.53 & 0.11 & 1.01 & 2.92 & 16.6 \\
17 & 29.79 & 29.86 & 0.43 & 1.08 & -6 & 29.95 \\
18 & 29.96 & 29.51 & 0 & 1.34 & -3.56 & 29.64 \\
19 & 29.9 & 29.91 & 0 & 0 & 0.23 & 29.9 \\
20 & 22.53 & 29.61 & 0 & 0.15 & 6.27 & 24.78 \\
21 & 30 & 29.36 & 0 & 1.04 & 2.91 & 15.09 \\
22 & 25.23 & 29.93 & 0 & 0.99 & -4.43 & 15.23 \\
23 & 7.46 & 28.59 & 0 & 0.73 & 1.35 & 27.53 \\
24 & 10.41 & 29.48 & 0 & 0.07 & -2.9 & 23.23 \\
\hline & & & & & &
\end{tabular}


Table 10. Power distribution for reducing pollution and considering the limitations of the upstream network exchange.

\begin{tabular}{ccccccc}
\hline \multirow{2}{*}{ Time } & MT (kW) & FC (kW) & PV (kW) & WT (kW) & Storage (kW) & Grid $\mathbf{( k W )}$ \\
\hline 1 & 6 & 4.63 & 0 & 1.43 & 10 & 29.94 \\
2 & 6.07 & 30 & 0 & 1.43 & 8.67 & 3.84 \\
3 & 30 & 3.02 & 0 & 1.43 & -8.63 & 24.17 \\
4 & 6.62 & 3.01 & 0 & 1.4 & 10 & 29.97 \\
5 & 6.02 & 29.04 & 0 & 1.42 & -9.47 & 29.99 \\
6 & 6 & 25.82 & 0 & 0.73 & -0.54 & 29.99 \\
7 & 6 & 29.65 & 0 & 0.13 & 4.22 & 30 \\
8 & 12.4 & 30 & 0.16 & 1.04 & 0.4 & 30 \\
9 & 6.01 & 27.18 & 2.95 & 1.42 & 8.45 & 30 \\
10 & 22.98 & 30 & 6.02 & 0 & -10 & 30 \\
11 & 10.41 & 16.42 & 8.35 & 6.99 & 5.83 & 30 \\
12 & 6 & 11.46 & 9.56 & 8.33 & 9.66 & 29.99 \\
13 & 6.72 & 3.04 & 19.11 & 3.13 & 10 & 29.99 \\
14 & 6 & 26.27 & 16.84 & 1.9 & -10 & 29.99 \\
15 & 13.62 & 29.84 & 6.3 & 1.42 & -5.16 & 29.99 \\
16 & 16.81 & 29.91 & 3.38 & 1.04 & -1.14 & 30 \\
17 & 29.99 & 23.79 & 0.44 & 0.24 & 0.55 & 29.98 \\
18 & 19.24 & 30 & 0 & 1.41 & 6.36 & 30 \\
19 & 19.47 & 30 & 0 & 1.03 & 9.5 & 30 \\
20 & 29.68 & 30 & 0 & 1.43 & -4.11 & 30 \\
21 & 6.54 & 30 & 0 & 0.53 & 10 & 29.94 \\
22 & 16.43 & 27.89 & 0 & 1.03 & -4.34 & 29.98 \\
23 & 6 & 18.58 & 0 & 0.7 & 9.73 & 30.01 \\
24 & 6 & 21.53 & 0 & 0.46 & 0.01 & 30 \\
\hline & & & & & &
\end{tabular}

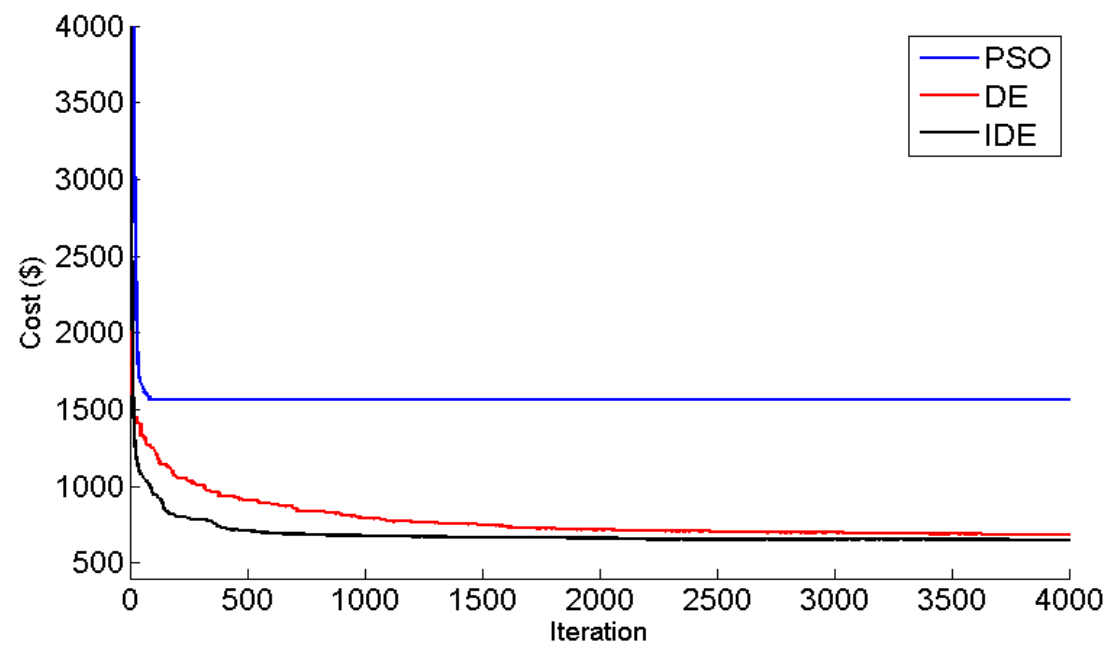

Figure 4. Cost convergence in different methods considering the limitations of power exchange with upstream network. 


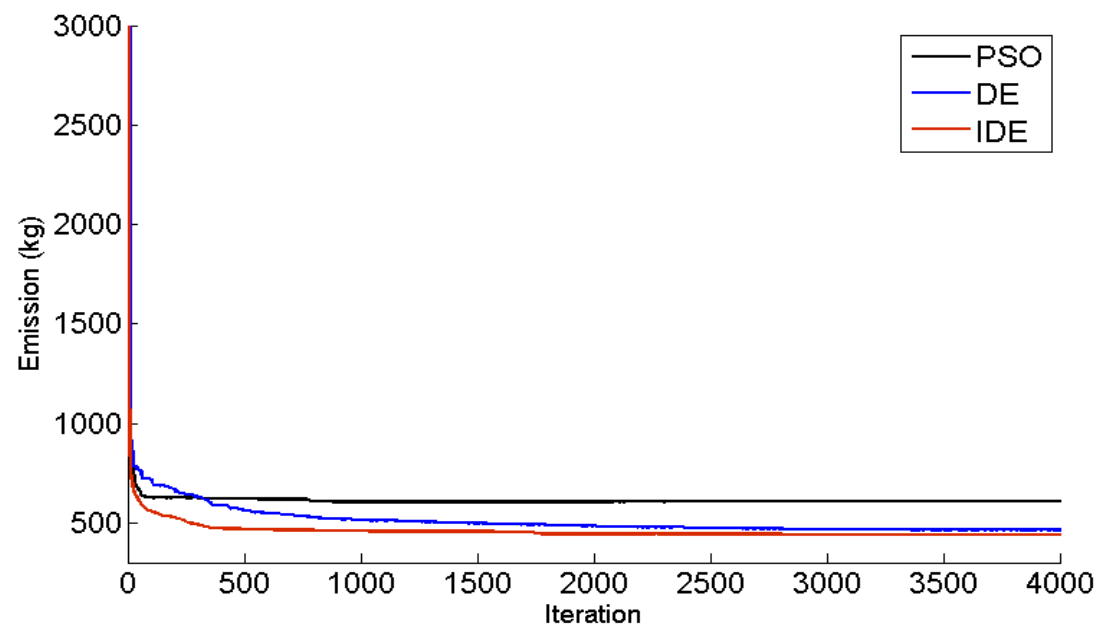

Figure 5. Convergence diagrams of gas emission in different methods considering the limitations of power exchange with upstream network.

Table 11. Comparison of the proposed method with other methods for reducing costs with considering the limitations of upstream network power exchange.

\begin{tabular}{ccccc}
\hline Method & $\begin{array}{c}\text { Best Answers } \\
\mathbf{( \$ )}\end{array}$ & $\begin{array}{c}\text { Average } \\
\text { Answers } \mathbf{( \$ )}\end{array}$ & $\begin{array}{c}\text { Worst Answers } \\
\mathbf{( \$ )}\end{array}$ & $\begin{array}{c}\text { Standard } \\
\text { Deviation } \mathbf{( \$ )}\end{array}$ \\
\hline PSO & 965.08 & 1051.35 & 1123.25 & 124.25 \\
DE & 682.3 & 682.15 & 695.21 & 11.22 \\
IDE & 661.37 & 677.27 & 687.5 & 10.81 \\
\hline
\end{tabular}

Table 12. Comparison of the proposed method with other methods for reducing gas emission with considering the limitations of upstream network power exchange.

\begin{tabular}{ccccc}
\hline Method & $\begin{array}{c}\text { Best Answers } \\
(\mathbf{k g})\end{array}$ & $\begin{array}{c}\text { Average } \\
\text { Answers (kg) }\end{array}$ & $\begin{array}{c}\text { Worst Answers } \\
\mathbf{( k g )}\end{array}$ & $\begin{array}{c}\text { Standard } \\
\text { Deviation } \mathbf{( k g )}\end{array}$ \\
\hline PSO & 1253.44 & 2494 & 3632.23 & 837.5 \\
DE & 461.4 & 479.77 & 499.77 & 11.47 \\
IDE & 449.16 & 463.4 & 485.38 & 10.46 \\
\hline
\end{tabular}

\subsection{Multi Objective Optimization}

3.2.1. Without Considering the Power Exchange Limitation with the Network

In this section, in order to solve the problem in a multi objective format, the limitation of power exchange with the upstream network is not considered. Figure 6 shows that the different approaches have come to close conclusions and the Pareto Front is very close to all three methods. Where NSIDE is non-dominated solution improved differential evolution, NSDE defines non-dominated solution differential evolution and NDPSO is non-dominated solution particle swarm optimization. Table 13 also shows the output of a sample response from the Pareto front of the NSIDE method. While the power generation capacity of all units is within the permissible range, it can be observed that at some times the network has largely purchased or sold electricity from the upstream network, which was due to the importance of cost and pollution in the optimization. When this problem was solved as a single objective, values of 618 and 136 were obtained for cost and pollution, respectively, whereas in the sample, these values are 753.97 and 394.74. 


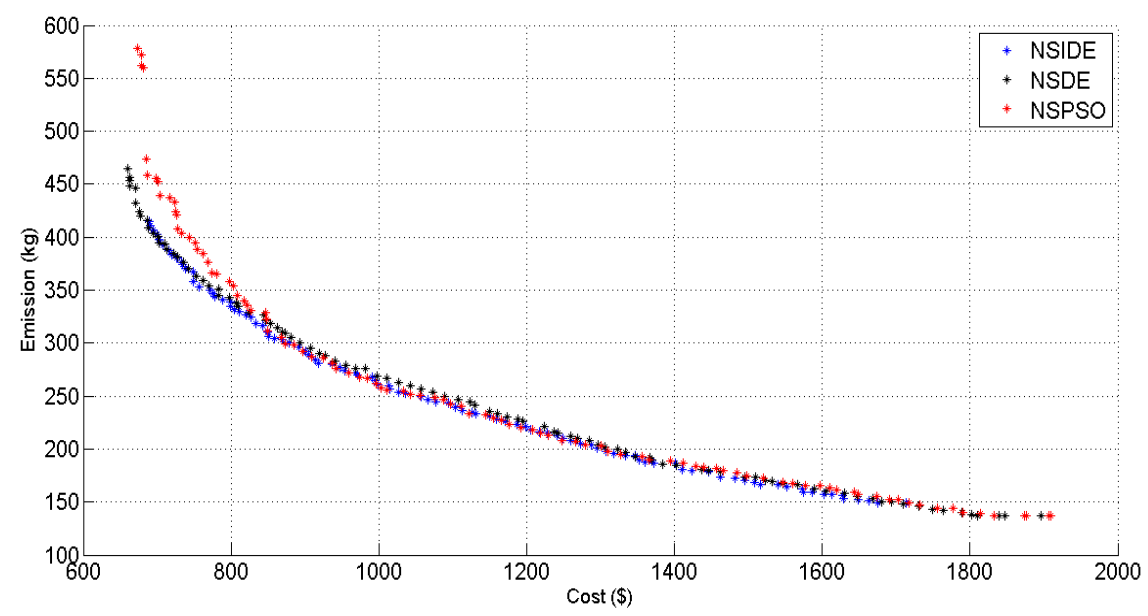

Figure 6. Comparing Pareto Fronts in different methods without considering the limits of upstream power exchange (cost and emission based).

Table 13. Power distribution in a Pareto Front sample answer without considering the limits of upstream power exchange.

\begin{tabular}{ccccccc}
\hline \multirow{2}{*}{ Time } & MT (kW) & FC (kW) & PV (kW) & WT (kW) & Storage (kW) & Grid $\mathbf{( k W ) ~}$ \\
\hline 1 & 6 & 3.01 & 0 & 0 & -10 & 52.99 \\
2 & 6 & 30 & 0 & 1.43 & 10 & 2.57 \\
3 & 6 & 3 & 0 & 1.43 & 0.36 & 39.08 \\
4 & 6 & 3 & 0 & 0 & -10 & 52 \\
5 & 6 & 3 & 0 & 1.43 & 10 & 36.57 \\
6 & 6 & 3 & 0 & 0.73 & 9.64 & 42.73 \\
7 & 30 & 3 & 0 & 0 & -10 & 46.99 \\
8 & 6 & 3.02 & 0.16 & 0 & -10 & 74.82 \\
9 & 6.05 & 30 & 0 & 1.43 & 0 & 38.53 \\
10 & 30 & 30 & 6.02 & 2.47 & 9.99 & 0.52 \\
11 & 30 & 30 & 8.36 & 7.02 & 10 & -7.38 \\
12 & 30 & 30 & 0 & 8.33 & 10 & -3.33 \\
13 & 6 & 30 & 0.01 & 0 & -10 & 45.98 \\
14 & 30 & 30 & 16.84 & 1.9 & 10 & -17.73 \\
15 & 30 & 30 & 0.01 & 1.43 & 10 & 4.42 \\
16 & 30 & 30 & 3.38 & 1.04 & -0.12 & 15.88 \\
17 & 6 & 3 & 0.44 & 1.43 & -10 & 84.13 \\
18 & 6.01 & 3 & 0 & 1.43 & -10 & 86.53 \\
19 & 6.01 & 3 & 0 & 0.01 & 10 & 70.98 \\
20 & 6.01 & 3 & 0 & 0 & -10 & 87.99 \\
21 & 6 & 29.89 & 0 & 0 & 10 & 31.19 \\
22 & 6 & 3 & 0 & 1.04 & 10 & 51.03 \\
23 & 6 & 3.01 & 0 & 0 & -10 & 65.98 \\
24 & 6 & 30 & 0 & 0 & 10 & 12.01 \\
\hline & & 30 & & & &
\end{tabular}

\subsubsection{With Considering the Power Exchange Limitation with the Network}

In order to illustrate the effectiveness of the NSIDE approach in solving the issue, this algorithm is implemented in the problem and its Pareto Front is compared with NSDE and NSPSO methods in Figure 7. It is quite clear that NSPSO is quite weak in solving this issue state and is not capable of solving this problem state, and NSDE has been defeated in all NSIDE cases. However, it has been shown in the preceding section that, without limiting the power exchange of different methods, it leads to similar solutions. The highlight of Pareto Front here is that it allows the user to choose the right answer. For example, a sample response from the Pareto Front with a total cost of $\$ 748.82$ and a pollution of 582.81 is shown in Table 14. By comparing the amount of gas emission and cost mentioned with the single-purpose mode ( $\$ 661$ and $449 \mathrm{~kg}$, respectively); that is, although in the multi-objective 
mode, each of the answers alone has a higher value than the single-objective mode, but for the intermediate mode, the answer is good, because both the cost and the contaminant are considered.

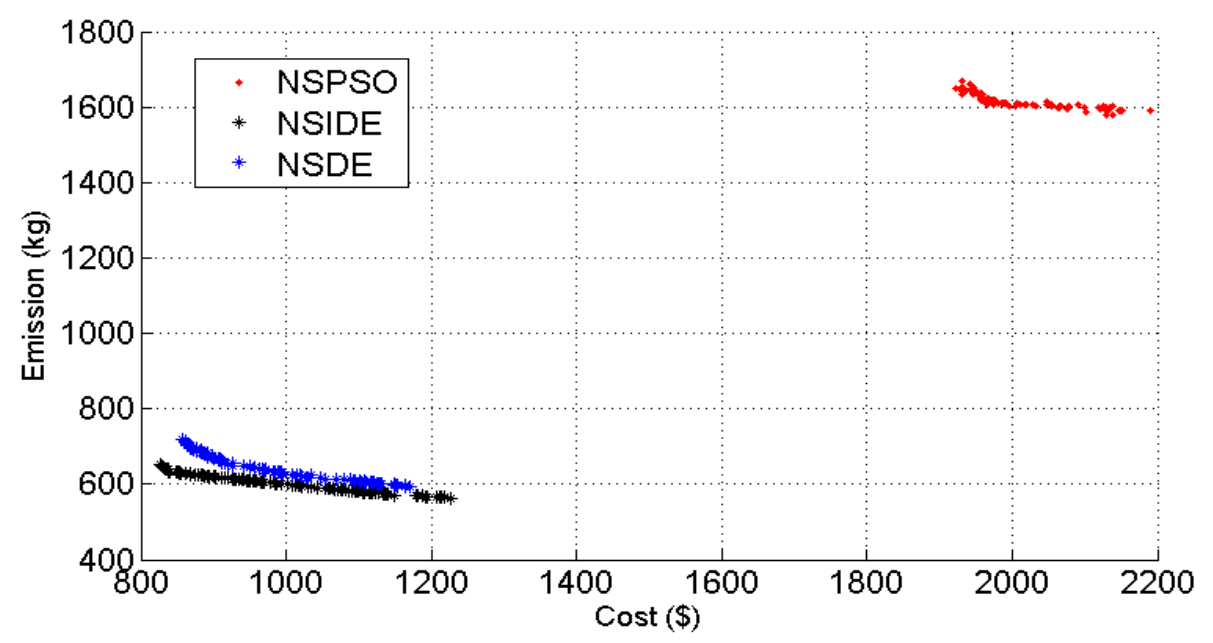

Figure 7. Comparing Pareto Fronts in different methods without considering the limits of upstream power exchange (cost and emission based).

Table 14. Power distribution in a Pareto Front sample answer without considering the limits of upstream power exchange.

\begin{tabular}{ccccccc}
\hline \multirow{2}{*}{ Time } & MT (kW) & FC (kW) & PV (kW) & WT (kW) & Storage (kW) & Grid (kW) \\
\hline 1 & 6 & 6.02 & 0 & 0 & 10 & 29.97 \\
2 & 6.03 & 3 & 0 & 1.36 & 9.74 & 29.89 \\
3 & 6 & 3 & 0 & 1.43 & 9.63 & 29.94 \\
4 & 6 & 23.39 & 0 & 1.43 & -9.8 & 29.97 \\
5 & 6 & 25.86 & 0 & 0 & -4.81 & 29.97 \\
6 & 6 & 29.99 & 0 & 0.73 & -4.69 & 29.98 \\
7 & 6.5 & 29.97 & 0 & 0.14 & 3.39 & 29.98 \\
8 & 6.01 & 26.78 & 0.16 & 1.04 & 10 & 29.99 \\
9 & 30 & 29.92 & 0 & 1.43 & -9.8 & 24.43 \\
10 & 30 & 29.99 & 6.02 & 2.47 & 10 & 0.52 \\
11 & 30 & 30 & 8.36 & 7.02 & 10 & -7.38 \\
12 & 30 & 30 & 9.56 & 8.33 & 10 & -12.88 \\
13 & 30 & 3.17 & 15.76 & 3.13 & -10 & 29.95 \\
14 & 30 & 30 & 16.84 & 1.9 & 10 & -17.73 \\
15 & 29.99 & 29.98 & 0 & 1.43 & -9.97 & 24.57 \\
16 & 29.98 & 30 & 0.01 & 1.04 & 9.85 & 9.13 \\
17 & 21.95 & 29.97 & 0.43 & 1.43 & 1.24 & 29.99 \\
18 & 30 & 30 & 0 & 1.42 & -4.41 & 29.97 \\
19 & 30 & 30 & 0 & 1.04 & -1.03 & 30 \\
20 & 30 & 29.98 & 0 & 1.43 & -4.4 & 29.98 \\
21 & 6.01 & 30 & 0 & 1.04 & 10 & 29.96 \\
22 & 6 & 30 & 0 & 0 & 5 & 29.99 \\
23 & 6 & 28.25 & 0 & 0.73 & 0.05 & 29.95 \\
24 & 7.52 & 29.99 & 0 & 0.49 & -10 & 30 \\
\hline & & & & & & \\
\end{tabular}

\subsection{Simulation in the Mode of Maximum Generation of Renewable Resources}

This section is intended to illustrate the importance of maximization of using RE sources. In this regard, the experiment was conducted in two parts: single objective and multi objective. In the single-objective part, each of the cost and pollution targets are considered separately, and in the multi-objective part, the NSIDE algorithm is used to optimize the problem. 


\subsubsection{Single Objective Optimization}

In this section, the objectives of reducing costs and reducing the amount of pollution are considered separately, each in two modes, with and without the limitation of power exchange with the network. The results of the total costs and gas emission obtained from this experiment are presented in Table 15 and compared with the normal operation mode of the network. Obviously, increasing the costs and reducing the pollution can be very effective if using renewable energy sources, and Table 15 also illustrates this fact. The distribution of power in units is presented in Tables 16-19 for different scenarios with and without network exchange constraints. Figures 8 and 9 also show the convergence of graphs with and without the limitations of upstream grid exchange. Obviously, taking into account the limitation will cost more to the users. In this part of the simulation, as the amount of WT and PV pollution is zero, and the amount of cost is higher than the other units, these two units are not considered in this part.

Table 15. Comparison of normal operation and operation with maximum amount of generation of renewable resources.

\begin{tabular}{ccc}
\hline Objectives & $\begin{array}{c}\text { Maximum Amount of Renewable } \\
\text { Power Generation }\end{array}$ & Normal Condition \\
\hline Cost (\$) with power exchange limitations & 704.87 & 661.37 \\
Emission (kg) with power exchange limitations & 428.15 & 419.16 \\
Cost (\$) with power exchange limitations & 677.51 & 618.91 \\
Emission (kg) with power exchange limitations & 136.58 & 136.49 \\
\hline
\end{tabular}

Table 16. Power distribution between generating resources to reduce costs without limiting power exchange total cost (\$677.51).

\begin{tabular}{ccccc}
\hline \multirow{2}{*}{ Time } & MT (kW) & FC $\mathbf{( k W )}$ & Storage $\mathbf{( k W )}$ & Grid $\mathbf{( k W )}$ \\
\hline 1 & 28.98 & 3.45 & -10 & 28.8 \\
2 & 6.93 & 3 & 10 & 26.23 \\
3 & 29.19 & 3.22 & 5.23 & 8.4 \\
4 & 6 & 29.32 & -10 & 23.66 \\
5 & 6 & 3 & 9.15 & 35.55 \\
6 & 29.77 & 3.21 & -10 & 39.19 \\
7 & 6.93 & 3 & 10 & 50.32 \\
8 & 6.2 & 29.07 & -10 & 46.24 \\
9 & 30 & 30 & -0.54 & 15.45 \\
10 & 30 & 29.73 & 10 & -1.46 \\
11 & 30 & 30 & -5.9 & 5.89 \\
12 & 30 & 29.69 & 7 & -13.76 \\
13 & 30 & 29.14 & 9.97 & -25.08 \\
14 & 29.73 & 30 & 10 & -21.19 \\
15 & 29.94 & 28.16 & -4.02 & 5.52 \\
16 & 28.59 & 29.93 & 7.27 & 13.24 \\
17 & 27.24 & 27.85 & -8.21 & 38.92 \\
18 & 6 & 3.33 & -10 & 85.4 \\
19 & 6.04 & 29.99 & 2.15 & 51.86 \\
20 & 7.27 & 8.25 & -9.25 & 77.88 \\
21 & 29.96 & 29.77 & 10 & 5.88 \\
22 & 30 & 27.25 & 9.67 & 2.84 \\
23 & 12.12 & 3.74 & -5.53 & 47.49 \\
24 & 6 & 7.03 & -10 & 51.82 \\
\hline
\end{tabular}


Table 17. Power distribution between generating resources to reduce costs without limitation of power exchange (total cost: \$704.87).

\begin{tabular}{ccccc}
\hline \multirow{2}{*}{ Time } & MT (kW) & FC $\mathbf{( k W )}$ & Storage $\mathbf{( k W )}$ & Grid $\mathbf{( k W )}$ \\
\hline 1 & 6.02 & 24.24 & -9.91 & 29.9 \\
2 & 6 & 3.19 & 9.62 & 29.26 \\
3 & 6 & 3 & 9.27 & 29.88 \\
4 & 13.6 & 3 & 2.68 & 29.87 \\
5 & 29.99 & 3.07 & -7.81 & 29.95 \\
6 & 6.22 & 29.92 & -4.01 & 30.02 \\
7 & 29.98 & 29.98 & -9.71 & 19.76 \\
8 & 13.27 & 30 & 0.05 & 29.84 \\
9 & 30 & 30 & -0.09 & 10.57 \\
10 & 30 & 30 & 10 & -1.61 \\
11 & 30 & 30 & 10 & -11.22 \\
12 & 30 & 30 & 10 & -17.36 \\
13 & 30 & 30 & 9.92 & -25.78 \\
14 & 30 & 30 & 0.06 & -11.45 \\
15 & 30 & 30 & -1.09 & 7.44 \\
16 & 30 & 30 & 1.09 & 13.41 \\
17 & 30 & 29.62 & -1.25 & 24.17 \\
18 & 30 & -4.69 & 30.06 \\
19 & 29.98 & 29.96 & -0.27 & 29.97 \\
20 & 29.01 & 29.99 & -4.11 & 29.83 \\
21 & 29.53 & 30 & 9.98 & 5.72 \\
22 & 29.99 & 30 & 0.05 & 9.93 \\
23 & 29.75 & 30 & -1.8 & 29.83 \\
24 & 6 & 29.96 & -9.99 & 29.95 \\
\hline & 7.48 & & &
\end{tabular}

Table 18. Power distribution between sources to reduce pollution without limiting power exchange (total pollution: $136.58 \mathrm{~kg}$ ).

\begin{tabular}{ccccc}
\hline \multirow{2}{*}{ Time } & MT (kW) & FC (kW) & Storage $\mathbf{( k W )}$ & Grid $\mathbf{( k W )}$ \\
\hline 1 & 6 & 3 & -9.99 & 51.22 \\
2 & 6 & 3 & 9.99 & 29.17 \\
3 & 6 & 3 & 10 & 29.22 \\
4 & 6 & 3 & 9.58 & 25.51 \\
5 & 6 & 3 & -10 & 56.06 \\
6 & 6 & 3 & -10 & 63.08 \\
7 & 6 & 3 & 5.32 & 68.83 \\
8 & 6 & 3 & -10 & 57.17 \\
9 & 6 & 3 & 8.43 & 53.82 \\
10 & 6 & 3 & 10 & 49.38 \\
11 & 6.01 & 3.01 & -10 & 60.23 \\
12 & 6 & 3 & 9.79 & 33.8 \\
13 & 6 & 3 & 9.43 & 25.29 \\
14 & 6 & 3 & -10 & 49.58 \\
15 & 6 & 3 & 10 & 47.34 \\
16 & 6 & 3 & -10 & 75.43 \\
17 & 6 & 3 & -9.99 & 83.61 \\
18 & 6 & 3 & 9.48 & 76.5 \\
19 & 6 & 3 & -9.98 & 89.56 \\
20 & 6 & 3 & 10 & 70.29 \\
21 & 6 & 3.02 & 9.92 & 56.92 \\
22 & 6 & 3 & -10 & 64.5 \\
23 & 6 & 3 & -10 & 65.39 \\
24 & 61 & 3 & -9.88 & 58.29 \\
\hline
\end{tabular}


Table 19. Distribution of power between generating sources to reduce pollution with considering power exchange limitation (total pollution: $428.15 \mathrm{~kg}$ ).

\begin{tabular}{ccccc}
\hline \multirow{2}{*}{ Time } & MT (kW) & FC $\mathbf{( k W )}$ & Storage $\mathbf{( k W )}$ & Grid $\mathbf{( k W )}$ \\
\hline 1 & 6.75 & 3.47 & 9.99 & 29.99 \\
2 & 6 & 3.01 & 9.81 & 29.37 \\
3 & 6 & 12.14 & 0.08 & 29.99 \\
4 & 6 & 23.1 & -9.88 & 29.99 \\
5 & 6 & 9.28 & 9.99 & 29.95 \\
6 & 6 & 25.62 & 0.47 & 29.99 \\
7 & 12.8 & 30 & -2.98 & 30 \\
8 & 6 & 29.97 & 6.53 & 29.99 \\
9 & 20.49 & 29.95 & -9.97 & 30.01 \\
10 & 11.45 & 18.99 & 7.96 & 30 \\
11 & 6.05 & 24.25 & -1.52 & 29.98 \\
12 & 16.41 & 3 & 3.24 & 30 \\
13 & 6.27 & 8.8 & -0.89 & 30 \\
14 & 6.01 & 15.83 & -3.24 & 30.01 \\
15 & 6.01 & 29.93 & 0.4 & 29.99 \\
16 & 29.38 & 25.08 & -9.98 & 30 \\
17 & 12.68 & 30 & 10 & 29.99 \\
18 & 19.1 & 30 & 6.12 & 30.01 \\
19 & 19.58 & 29.82 & 9.33 & 29.98 \\
20 & 17.84 & 29.99 & 7.39 & 30 \\
21 & 10.74 & 30 & 4.96 & 30 \\
22 & 8.13 & 30 & 1.57 & 29.99 \\
23 & 12.5 & 29.96 & -8.37 & 29.99 \\
24 & 8.58 & 9.84 & 8.98 & 29.99 \\
\hline
\end{tabular}

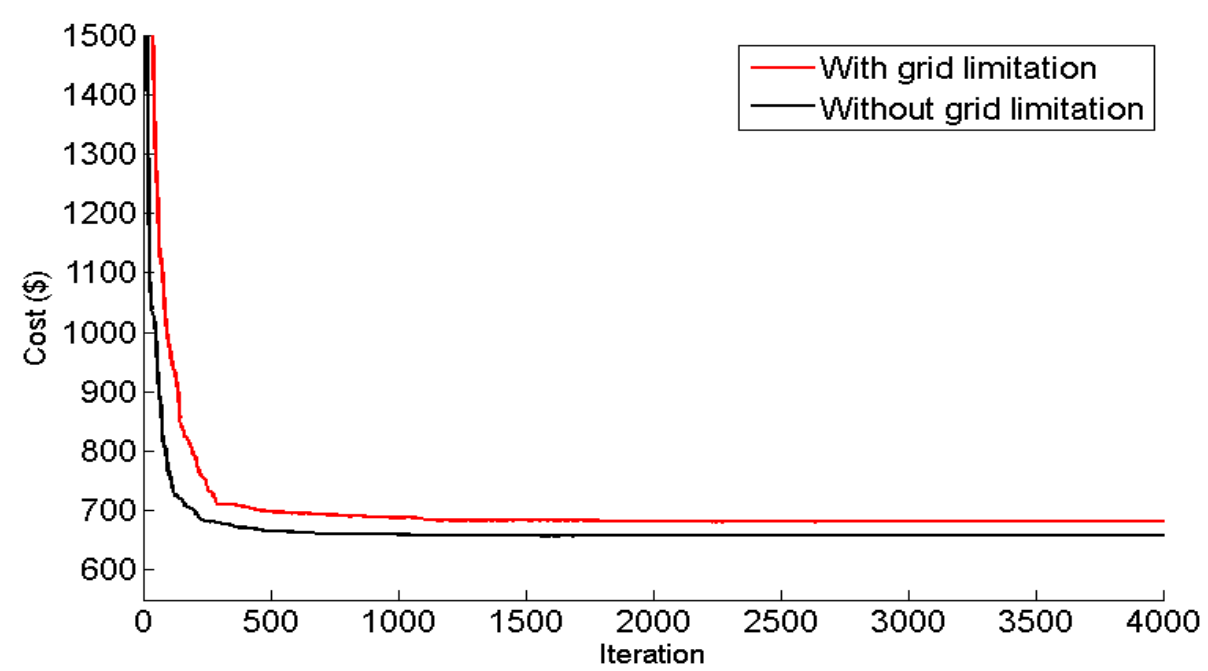

Figure 8. Comparison of cost convergence with and without the limitations of upstream power exchange. 


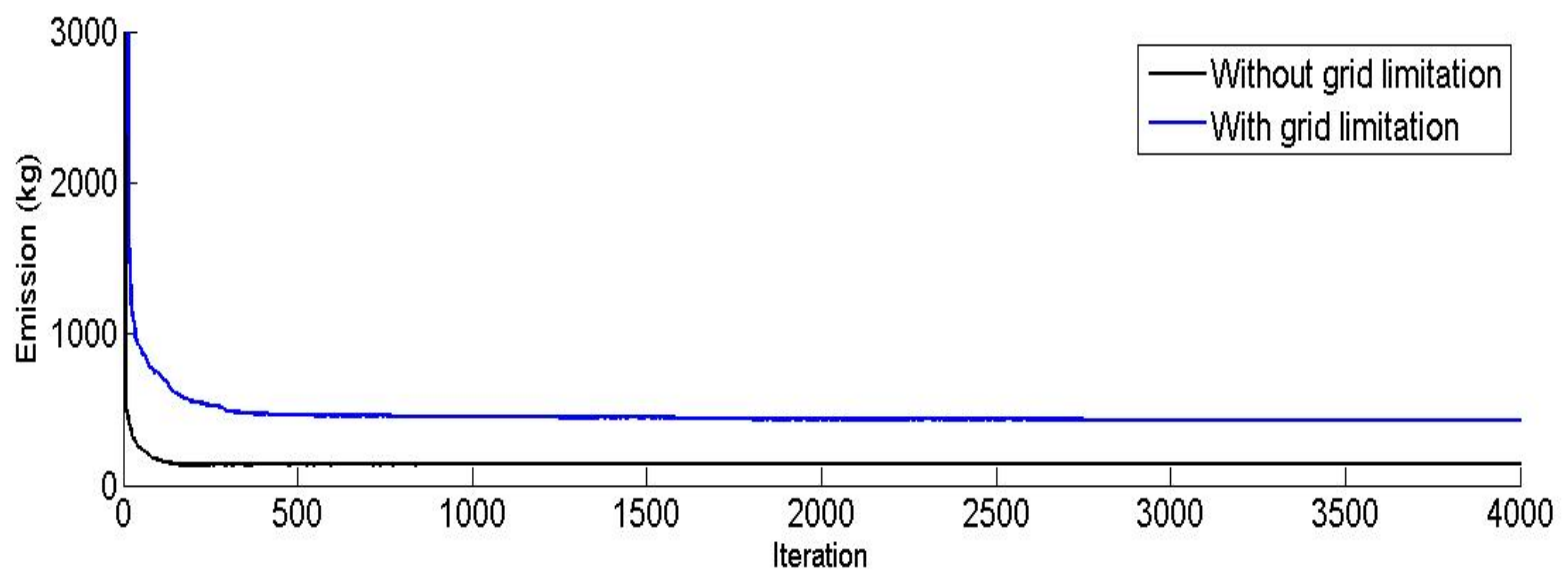

Figure 9. Comparison of pollution convergence with and without upstream transmission power limitations.

\subsubsection{Multi Objective Optimization}

When multiple objectives are also considered in optimizing the utilization of the MG by maximizing the use of renewables, it has significant effects on the network. These effects are presented in the form of the Pareto front in Figure 10. The distance between these two fronts indicates the positive impact of maximization of using RE sources, which confirms the ability of reduction in the costs for maximizing use of RE sources. In this case, a comparison is also made between the proposed method and the other methods in two cases with and without grid limitations in Figures 11 and 12, which illustrates the superiority of the proposed method over other methods.

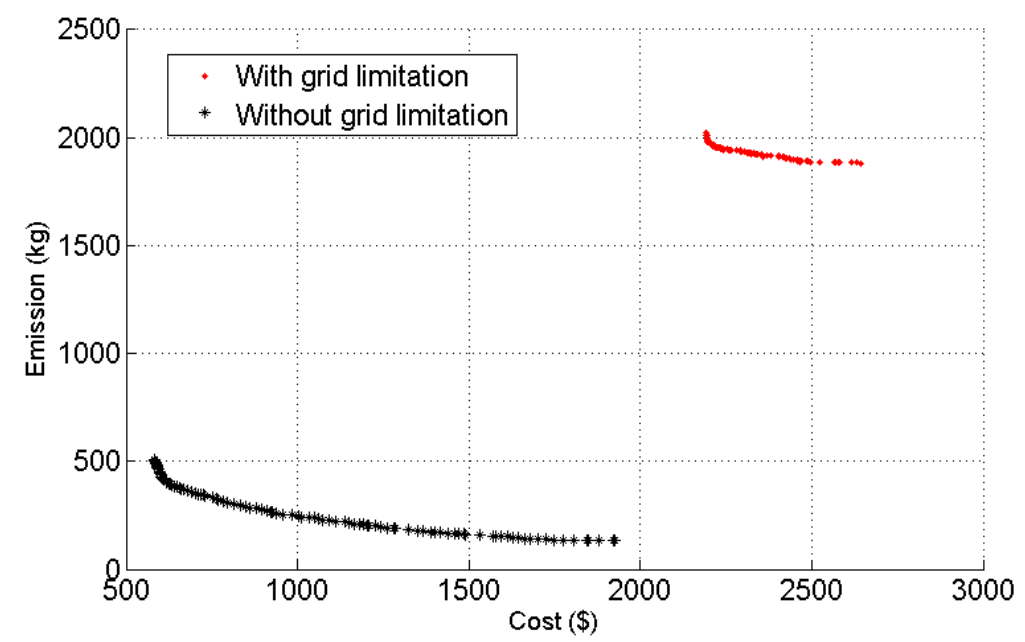

Figure 10. Comparison of Pareto Fronts with and without limitation of upstream grid exchange (cost and emission based). 


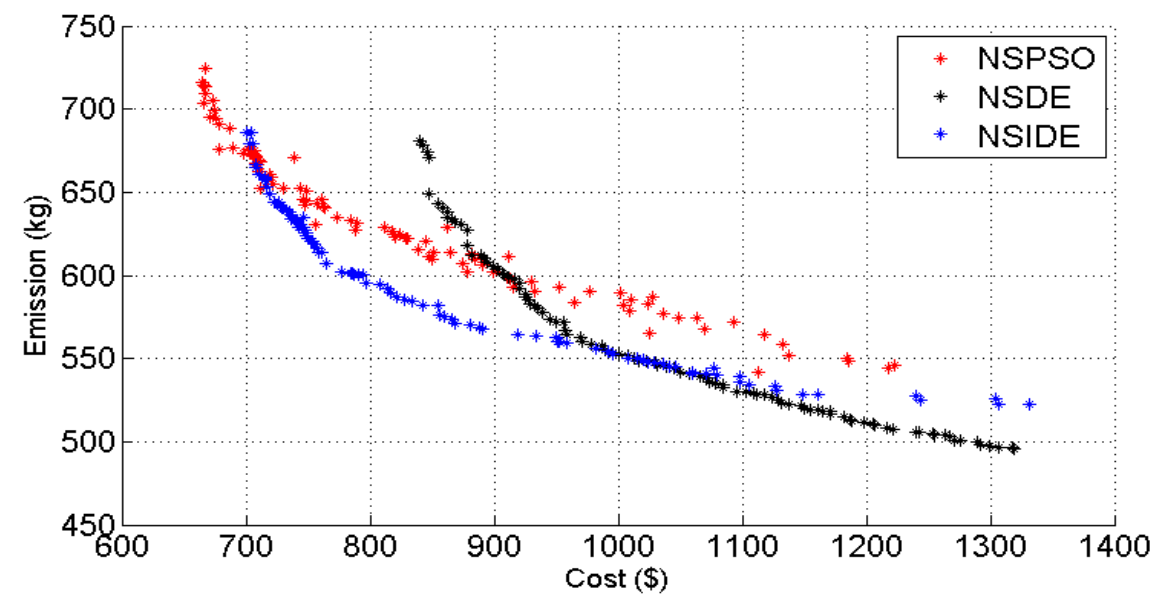

Figure 11. Results of implementing different methods considering the limitations of upstream grid power exchange (cost and emission based).

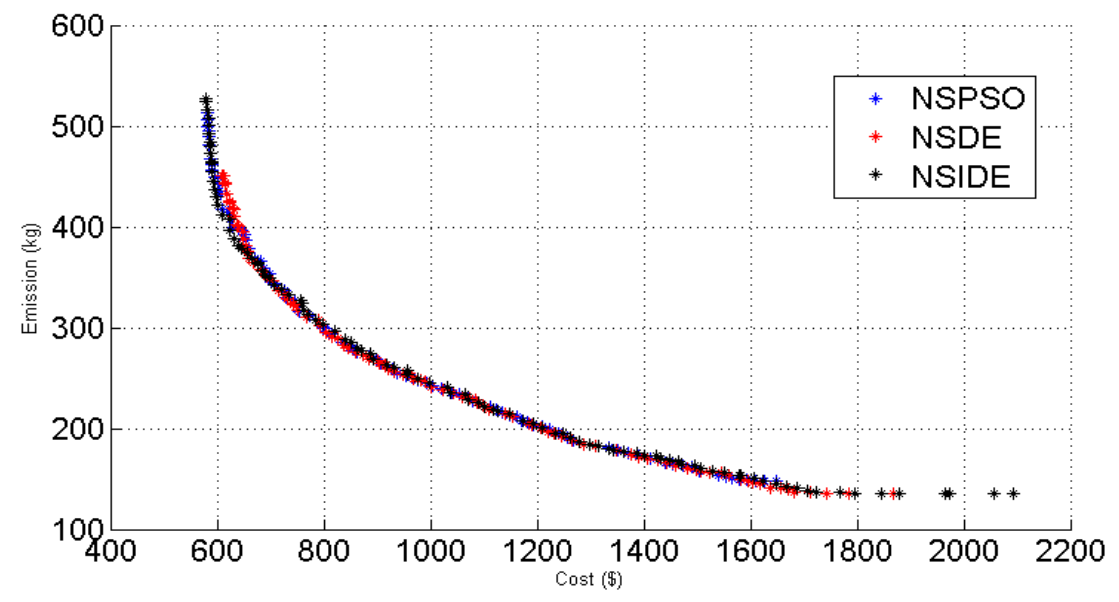

Figure 12. The results of implementing different methods without considering the limitations of upstream power exchange (cost and emission based).

\subsection{Sensitivity Analysis}

In order to show the sensitivity, the algorithm has been implemented to solve the issue of optimal number of populations in the problem of optimal operation of MG with different initial populations in two single-objective and multi-objective modes. Populations of $25,50,75$, and 100 are intended to solve the problem. Table 20 shows the impact of population change on cost and Table 21 displays the impact of initial population on pollution. Increasing the initial population has improved the answers. On the other hand, the running time of the program also increases. Figures 13 and 14 show the effects of the initial population on convergence respectively. It is clear that increasing population size improves the convergence of graphs. Figure 15 shows the Pareto Fronts with different populations; an increase in population makes the Fronts more dominant. 
Table 20. The results of implementing the proposed algorithm with different initial populations with the aim of reducing costs.

\begin{tabular}{cccccc}
\hline Initial Population & Best Answer & Average Answers & Worst Answer & Standard Deviation & Time \\
\hline 25 & 729.1 & 1072.94 & 1658.61 & 337.1 & 38 \\
50 & 669.55 & 739.35 & 1012.41 & 104.38 & 63 \\
75 & 656.33 & 686.9 & 726.5 & 22.07 & 95 \\
100 & 647.74 & 683.64 & 738.59 & 28.95 & 124 \\
\hline
\end{tabular}

Table 21. The results of implementing the proposed algorithm with different initial populations for reducing pollution.

\begin{tabular}{cccccc}
\hline Initial Population & Best Answer & Average Answers & Worst Answer & Standard Deviation & Time \\
\hline 25 & 521.8 & 659.84 & 945.08 & 160.92 & 34 \\
50 & 485.28 & 502.5 & 571.94 & 26.45 & 87 \\
75 & 457.07 & 467.36 & 486.96 & 8.58 & 13.22 \\
100 & 443.91 & 460.24 & 491.49 & 103 \\
\hline
\end{tabular}

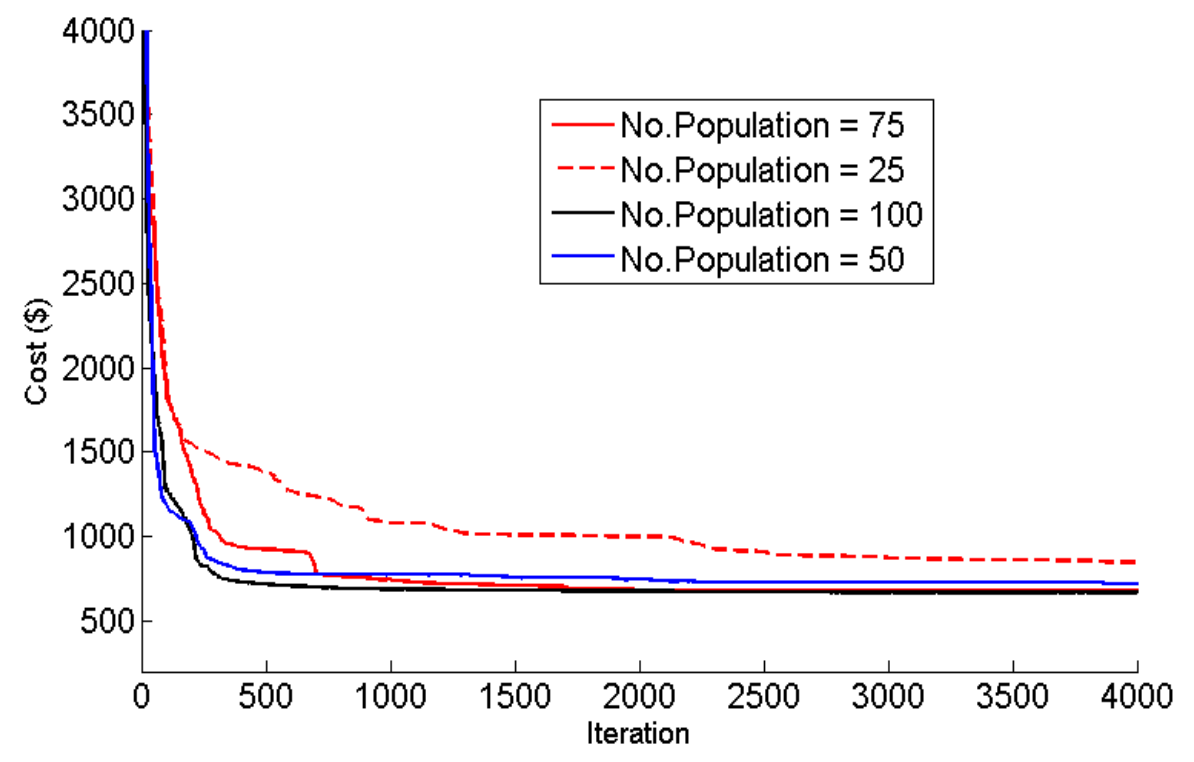

Figure 13. The influence of initial population on cost convergence.

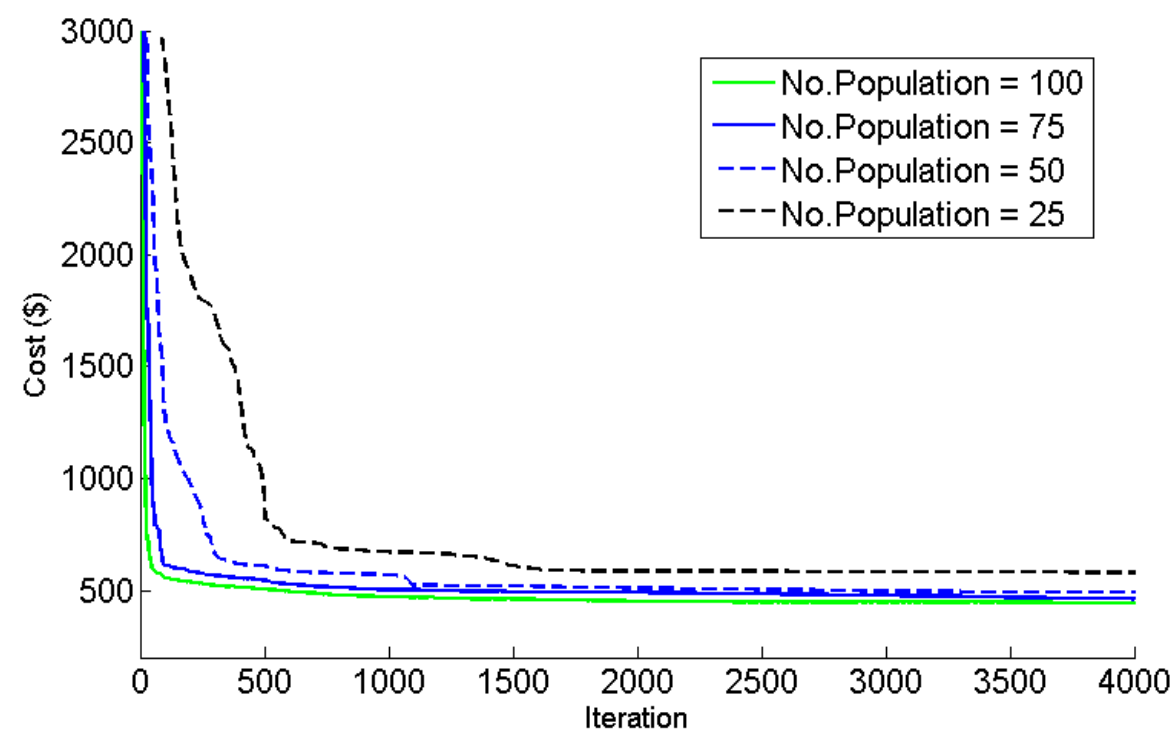

Figure 14. Impact of initial population on convergence of pollution (cost based). 


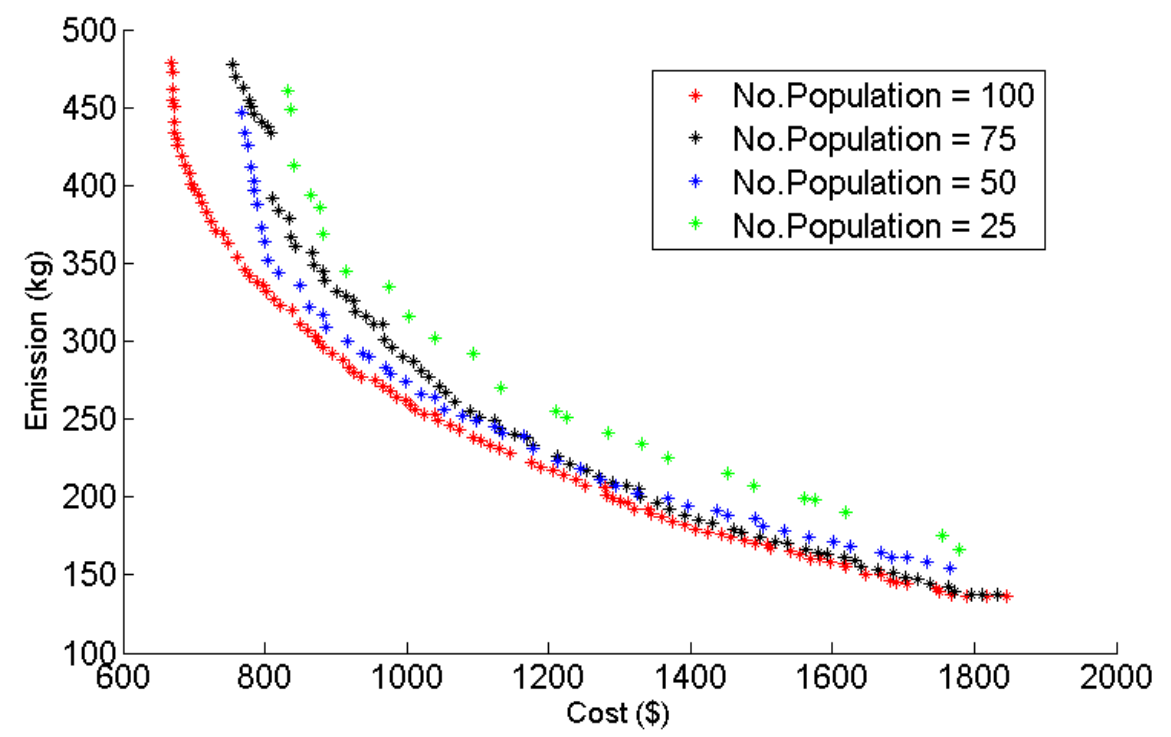

Figure 15. Impact of population changes on the Pareto Front (cost and emission based).

Figure 16 compares normal loading and survivability of loads during different hours a day. As can be seen from Figure 16, a significant proportion of loads in the MG has been supplied, which in turn shows the effectiveness of proposed method to enhance power system resilience after long-time outage.

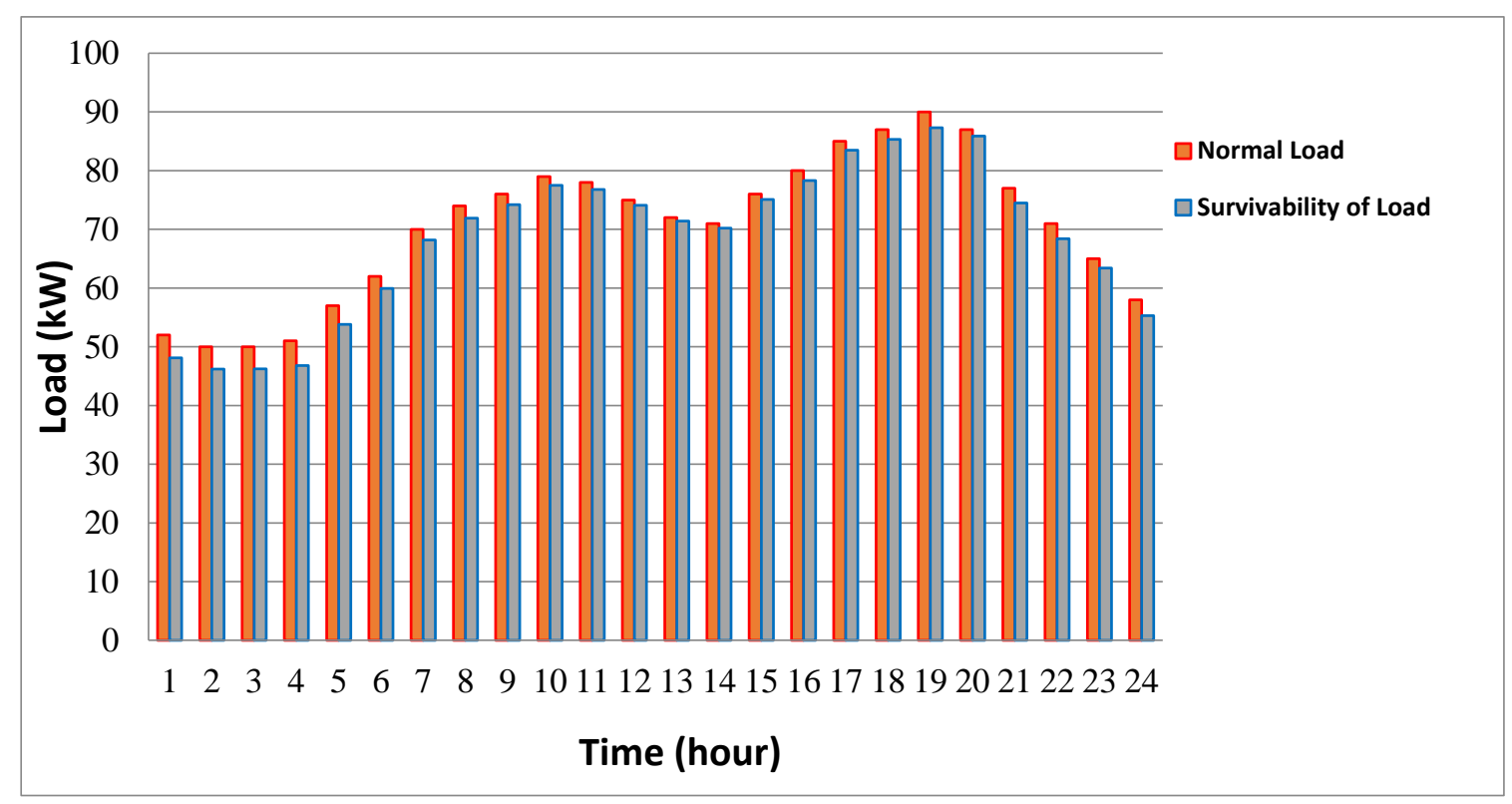

Figure 16. Survivability of loads during different hours a day.

\subsection{Future Works}

In this paper, the power required by consumers is provided through a MG in which various and renewable distributed generation sources are used. Additionally, by managing production in these resources and using simultaneous optimization of targets using intelligent Pareto algorithm, it has caused the reduction of costs and the amount of environmental pollution. The use of important technology such as MGs, consideration of important goals such as environmental and economic issues, as well as the use of Pareto method and system optimization with multiple goals and improving the IDE algorithm are among the important points. The behavior of renewable resources due to their unpredictable 
performance, in terms of consumer load pattern and market competition, is another case that has been studied in this study. In addition, the system studied in this paper can be compared with other new evolutionary and improved algorithms.

With the development of communication systems and systems intelligence, the risks of cyber and malicious attacks are increasing, in this regard, systems should be designed and improved to be more resilient and resistant to these malicious attacks. So, in future work, intelligent power systems can be optimized to withstand cyber and physical attacks such as storms and earthquakes, and power management can be optimized and studied with applicable and efficient strategies.

\section{Conclusions}

Having an optimal energy management and power dispatch in smart MGs considering different factors such as cost or air pollutant effects can be highly effective in modern developed society. In this research, an improved multi-objective DE algorithm was proposed and used in a multi-operation energy management form in a smart MG system. One of the main innovations of the suggested technique is that the modifying meta-heuristic parameters within this model, unlike conventional methods, have been allocated to the self-adaptive system.

In order to demonstrate the high efficiency of the IMODE algorithm in solving the problem of optimal operation of the MG in both single-objective and multi-objective modes, this algorithm has been carried out on different problems. In order to show the impact of renewable energy on the cost, in the simulations, the operation has been solved with maximum participation of renewable energy resources. Additionally, gas emission and air pollution have been considered in simulation. In addition to this, presenting an efficient concept of energy exchange between the MG and the main power network can be highly beneficial for both objectives in the grid-connected mode. Additionally, the sensitivity analysis on the number of populations in the meta-heuristic algorithms has been performed, and the results of simulation were compared and analyzed. The feasibility and effectiveness of proposed method has been confirmed by applying on a study case system. Besides, using improved self-adaptive DE in optimization issues not only can provide the best respondent to the designing and planning requirements, but can satisfy emission and economic aims with an admissible precision.

Author Contributions: Conceptualization, Formal analysis, Data curation, Investigation, Software, Resources and Writing-Original Draft, performed by M.G. and M.D.; Project Administration, Supervision done by T.N., and H.H.A.; Validation done by T.N., P.S., A.A.-H. and H.H.A.; WritingReview \& Editing, Visualization, Methodology and Funding acquisition are done by P.S., A.A.-H. and H.H.A. All authors contributed equally to this paper. All authors have read and agreed to the published version of the manuscript.

Funding: The work of Hassan Haes Alhelou was supported in part by the Science Foundation Ireland (SFI) through the SFI Strategic Partnership Programme under Grant SFI/15/SPP/E3125, and in part by the UCD Energy Institute. The opinions, findings and conclusions or recommendations expressed in this material are those of the authors and do not necessarily reflect the views of the Science Foundation Ireland. For the purpose of Open Access, the author has applied a CC BY public copyright license to any Author Accepted Manuscript version arising from this submission. The work of Amer Al-Hinai was supported by SQU under grant SR/ENG/ECED/17/1.

Informed Consent Statement: Not applicable.

Data Availability Statement: Data is contained within the article.

Conflicts of Interest: The authors declare no conflict of interest. 


\section{References}

1. Baghaee, H.R.; Mirsalim, M.; Gharehpetian, G.B.; Talebi, H.A. A decentralized power management and sliding mode control strategy for hybrid AC/DC microgrids including renewable energy resources. IEEE Trans. Ind. Inform. 2017. [CrossRef]

2. Fouladi, E.; Baghaee, H.R.; Bagheri, M.; Gharehpetian, G.B. Power Management of Microgrids Including PHEVs Based on Maximum Employment of Renewable Energy Resources. IEEE Trans. Ind. Appl. 2020, 56, 5299-5307. [CrossRef]

3. Dehghani, M.; Ghiasi, M.; Niknam, T.; Kavousi-Fard, A.; Shasadeghi, M.; Ghadimi, N.; Taghizadeh-Hesary, F. BlockchainBased Securing of Data Exchange in a Power Transmission System Considering Congestion Management and Social Welfare. Sustainability 2021, 13, 90. [CrossRef]

4. Fathi, M.; Ghiasi, M. Optimal DG Placement to Find Optimal Voltage Profile Considering Minimum DG Investment Cost in Smart Neighborhood. Smart Cities 2019, 2, 328-344. [CrossRef]

5. Dufo-Lopez, R.; Bernal-Agustín, J.L.; Contreras, J. Optimization of control strategies for stand-alone renewable energy systems with hydrogen storage. Renew. Energy 2007, 32, 1102-1126. [CrossRef]

6. Tiwari, P.; Manas, M.; Jan, P.; Nemec, Z.; Radovan, D.; Mahanta, P.; Trivedi, G. A Review on Microgrid Based on Hybrid Renewable Energy Sources in South-Asian Perspective. Technol. Econ. Smart Grids Sustain. Energy 2017, 2, 10. [CrossRef]

7. Lidula, N.; Rajapakse, A. Microgrids research: A review of experimental microgrids and test systems. Renew. Sustain. Energy Rev. 2011, 15, 186-202. [CrossRef]

8. Ghiasi, M.; Esmaeilnamazi, S.; Ghiasi, R.; Fathi, M. Role of Renewable Energy Sources in Evaluating Technical and Economic Efficiency of Power Quality. Technol. Econ. Smart Grids Sustain. Energy 2020, 5, 1. [CrossRef]

9. Song, Y.; Chen, X.; Lin, J.; Liu, F.; Qiu, Y. Stochastic processes in renewable power systems: From frequency domain to time domain. Sci. China Technol. Sci. 2019, 62, 2093-2103. [CrossRef]

10. Zhong, Q.; Buckley, S.; Vassallo, A.; Sun, Y. Energy cost minimization through optimization of EV, home and workplace battery storage. Sci. China Technol. Sci. 2018, 61, 761-773. [CrossRef]

11. Ghiasi, M. Detailed study, multi-objective optimization, and design of an AC-DC smart microgrid with hybrid renewable energy resources. Energy 2019, 169, 496-507. [CrossRef]

12. Ghiasi, M. Technical and economic evaluation of power quality performance using FACTS devices considering renewable generations. Renew. Energy Focus 2019, 29, 49-62. [CrossRef]

13. Ghiasi, M.; Ghadimi, N.; Ahmadinia, E. An analytical methodology for reliability assessment and failure analysis in distributed power system. SN Appl. Sci. 2018, 1, 44. [CrossRef]

14. Ghiasi, M. A comparative study on common power flow techniques in the power distribution system of the Tehran metro. Teh. Glas. 2018, 12, 244-250. [CrossRef]

15. Yu, D.; Zhang, T.; He, G.; Nojavan, S.; Jermsittiparsert, K.; Ghadimi, N. Energy management of wind-PV-storage-grid based large electricity consumer using robust optimization technique. J. Energy Storage 2020, 27, 101054. [CrossRef]

16. Duan, P.; Soleimani, H.; Ghazanfari, A.; Dehghani, M. Distributed Energy Management in Smart Grids Based on Cloud-Fog Layer Architecture Considering PHEVs. IEEE Trans. Ind. Appl. 2020. [CrossRef]

17. Dehghani, M.; Kavousi-Fard, A.; Niknam, T.; Avatefipour, O. A robust voltage and current controller of parallel inverters in smart island: A novel approach. Energy 2021, 214, 118879. [CrossRef]

18. Khooban, M.-H.; Dehghani, M.; Dragičević, T. Hardware-in-the-loop simulation for the testing of smart control in grid-connected solar power generation systems. Int. J. Comput. Appl. Technol. 2018, 58, 116-128. [CrossRef]

19. Karimi, H.; Niknam, T.; Aghaei, J.; GhasemiGarpachi, M.; Dehghani, M. Switches optimal placement of automated distribution networks with probability customer interruption cost model: A case study. Int. J. Electr. Power Energy Syst. 2021, 127, 106708. [CrossRef]

20. Barani, M.; Aghaei, J.; Akbari, M.A.; Niknam, T.; Farahmand, H.; Korpås, M. Optimal partitioning of smart distribution systems into supply-sufficient microgrids. IEEE Trans. Smart Grid 2018, 10, 2523-2533. [CrossRef]

21. Dehghani, M.; Khooban, M.H.; Niknam, T.; Rafiei, S. Time-varying sliding mode control strategy for multibus low-voltage microgrids with parallel connected renewable power sources in islanding mode. J. Energy Eng. 2016, 142, 05016002. [CrossRef]

22. Yao, Y.; Tian, F.; Mei, F.; Fu, J.; Dai, B.; Yu, W. Dynamical economic dispatch using distributed barrier function-based optimization algorithm. Sci. China Technol. Sci. 2019, 62, 2104-2112. [CrossRef]

23. Ghiasi, M.; Dehghani, M.; Niknam, T.; Baghaee, H.R.; Padmanaban, S.; Gharehpetian, G.B.; Aliev, H. Resiliency/Cost-based Optimal Design of Distribution Network to Maintain Power System Stability against Physical Attacks: A Practical Study Case. IEEE Access 2021, 9, 43862-43875. [CrossRef]

24. Ghiasi, M.; Dehghani, M.; Niknam, T.; Kavousi-Fard, A.; Siano, P.; Alhelou, H.H. Cyber-Attack Detection and Cyber-Security Enhancement in Smart DC-Microgrid Based on Blockchain Technology and Hilbert Huang Transform. IEEE Access 2021, 9, 29429-29440. [CrossRef]

25. Boqiang, R.; Chuanwen, J. A review on the economic dispatch and risk management considering wind power in the power market. Renew. Sustain. Energy Rev. 2009, 13, 2169-2174. [CrossRef]

26. Farag, A.; Al-Baiyat, S.; Cheng, T. Economic load dispatch multiobjective optimization procedures using linear programming techniques. IEEE Trans. Power Syst. 1995, 10, 731-738. [CrossRef]

27. El-Hendawi, M.; Wang, Z. An ensemble method of full wavelet packet transform and neural network for short term electrical load forecasting. Electr. Power Syst. Res. 2020, 182, 106265. [CrossRef] 
28. Megahed, T.F.; Abdelkader, S.M.; Zakaria, A. Energy Management in Zero-Energy Building Using Neural Network Predictive Control. IEEE Internet Things J. 2019, 6, 5336-5344. [CrossRef]

29. Khaloie, H.; Abdollahi, A.; Shafie-khah, M.; Anvari-Moghaddam, A.; Nojavan, S.; Siano, P.; Catalão, J.P.S. Coordinated windthermal-energy storage offering strategy in energy and spinning reserve markets using a multi-stage model. Appl. Energy 2020, 259, 114168. [CrossRef]

30. Gaing, Z.-L. Particle swarm optimization to solving the economic dispatch considering the generator constraints. IEEE Trans. Power Syst. 2003, 18, 1187-1195. [CrossRef]

31. Jayabarathi, T.; Jayaprakash, K.; Jeyakumar, D.; Raghunathan, T. Evolutionary programming techniques for different kinds of economic dispatch problems. Electr. Power Syst. Res. 2005, 73, 169-176. [CrossRef]

32. El-Emam, R.S.; Dincer, I. Assessment and Evolutionary Based Multi-Objective Optimization of a Novel Renewable-Based Polygeneration Energy System. J. Energy Resour. Technol. 2017, 139, 012003. [CrossRef]

33. Alarcon-Rodriguez, A.; Ault, G.; Galloway, S. Multi-objective planning of distributed energy resources: A review of the state-ofthe-art. Renew. Sustain. Energy Rev. 2010, 14, 1353-1366. [CrossRef]

34. Sadegheih, A. Optimal design methodologies under the carbon emission trading program using MIP, GA, SA, and TS. Renew. Sustain. Energy Rev. 2011, 15, 504-513. [CrossRef]

35. Qu, B.-Y.; Zhu, Y.; Jiao, Y.; Wu, M.; Suganthan, P.N.; Liang, J. A survey on multi-objective evolutionary algorithms for the solution of the environmental/economic dispatch problems. Swarm Evol. Comput. 2018, 38, 1-11. [CrossRef]

36. Elattar, E.E. Environmental economic dispatch with heat optimization in the presence of renewable energy based on modified shuffle frog leaping algorithm. Energy 2019, 171, 256-269. [CrossRef]

37. Mahdi, F.P.; Vasant, P.; Abdullah-Al-Wadud, M.; Watada, J.; Kallimani, V. A quantum-inspired particle swarm optimization approach for environmental/economic power dispatch problem using cubic criterion function. Int. Trans. Electr. Energy Syst. 2018, 28, e2497. [CrossRef]

38. Ma, S.; Wang, Y.; Lv, Y. Multiobjective environment/economic power dispatch using evolutionary multiobjective optimization. IEEE Access 2018, 6, 13066-13074. [CrossRef]

39. He, X.; Yu, J.; Huang, T.; Li, C. Distributed power management for dynamic economic dispatch in the multimicrogrids environment. IEEE Trans. Control Syst. Technol. 2018, 27, 1651-1658. [CrossRef]

40. Chen, J.; Qi, B.; Peng, K.; Li, Y.; Zhao, Y. Conditional value-at-credibility for random fuzzy wind power in demand response integrated multi-period economic emission dispatch. Appl. Energy 2020, 261, 114337. [CrossRef]

41. Prada, M.; Prada, I.F.; Cristea, M.; Popescu, D.E.; Bungău, C.; Aleya, L.; Bungău, C.C. New solutions to reduce greenhouse gas emissions through energy efficiency of buildings of special importance-Hospitals. Sci. Total Environ. 2020, 718, 137446. [CrossRef] [PubMed]

42. Prada, M.; Popescu, D.; Bungau, C.; Pancu, R.; Bungau, C. Parametric studies on European 20-20-20 energy policy targets in university environment. J. Environ. Prot. Ecol. 2017, 18, 1146-1157.

43. Alavi, S.A.; Ahmadian, A.; Aliakbar-Golkar, M. Optimal probabilistic energy management in a typical micro-grid based-on robust optimization and point estimate method. Energy Convers. Manag. 2015, 95, 314-325. [CrossRef]

44. Lin, C.-M.; Gen, M. Multi-criteria human resource allocation for solving multistage combinatorial optimization problems using multiobjective hybrid genetic algorithm. Expert Syst. Appl. 2008, 34, 2480-2490. [CrossRef]

45. Chang, P.-C.; Chen, S.-H.; Liu, C.-H. Sub-population genetic algorithm with mining gene structures for multiobjective flowshop scheduling problems. Expert Syst. Appl. 2007, 33, 762-771. [CrossRef]

46. Storn, R.; Price, K. Differential evolution-a simple and efficient heuristic for global optimization over continuous spaces. J. Glob. Optim. 1997, 11, 341-359. [CrossRef]

47. Qu, B.Y.; Suganthan, P.N. Constrained multi-objective optimization algorithm with an ensemble of constraint handling methods. Eng. Optim. 2011, 43, 403-416. [CrossRef]

48. Qian, F.; Xu, B.; Qi, R.; Tianfield, H. Self-adaptive differential evolution algorithm with $\alpha$-constrained-domination principle for constrained multi-objective optimization. Soft Comput. 2012, 16, 1353-1372. [CrossRef] 